\title{
PREPRINT
}

\section{From ego depletion to self-control fatigue: A review of criticisms along with new perspectives for the investigation and replication of a multicomponent phenomenon}

\author{
Cyril Forestier ${ }^{1 *}$, Margaux de Chanaleilles², Matthieu P. Boisgontier ${ }^{3,4}$, Aïna Chalabaev²
}

\author{
${ }^{1}$ Laboratoire Motricité, Interactions, Performance, MIP - EA4334, Le Mans Université, Le Mans, France \\ ${ }^{2}$ Laboratoire SENS, Univ. Grenoble Alpes, Grenoble, France \\ ${ }^{3}$ School of Rehabilitation Sciences, Faculty of Health Sciences, University of Ottawa, Ottawa, Canada \\ ${ }^{4}$ Bruyère Research Institute, Ottawa, Canada \\ *Corresponding author: 7 Avenue Olivier Messiaen, 72000 Le Mans, France; cyril.forestier@univ-lemans.fr; \\ @CForestier_PhD (C. Forestier)
}

All the authors listed in the by-line have agreed to the by-line order and to the submission of the manuscript in this form.

\begin{abstract}
The replication crisis in psychology has led to question popular phenomena such as ego depletion, which has been criticized after studies failed to replicate. Here, we describe limitations in the literature that contributed to these failures and suggest how they may be addressed. At the theoretical level, the literature focuses on two out of at least eight identified auxiliary hypotheses. Thus, the majority of the hypotheses related to the three core assumptions of the ego-depletion theory have been overlooked, thereby preventing the rejection of the theory as a whole. At the experimental level, we argue that the low replicability of ego-depletion studies could be explained by the absence of a comprehensive, integrative, and falsifiable definition of self-control, which is central to the concept of ego depletion; by an unclear or absent distinction between ego depletion and mental fatigue, two phenomena that rely on different processes; and by the low validity of the tasks used to induce ego depletion. Finally, we make conceptual and methodological suggestions for a more rigorous investigation of ego depletion, discuss the necessity to take into account its dynamic and multicomponent nature, and suggest using the term self-control fatigue instead.
\end{abstract}

Keywords: ego depletion, self-control fatigue, resources, willingness, capacity 


\section{A History of Ego-Depletion Discoveries and Controversies}

\subsection{A History of Ego Depletion}

Originally, ego depletion referred to a temporary reduction in the capacity to engage in selfcontrol (e.g., controlling behavior, making choices, initiating an action), caused by prior selfcontrol exertion that depleted a common resource (Baumeister et al., 1998). Ego depletion was construed as a state of impaired self-control that could evolve. This construal contrasted with approaches that considered self-control to be a trait (Tangney et al., 2004; for a discussion about self-control state and trait, see de Ridder et al., 2018)1.

Baumeister et al. tested their theory with the sequential-task paradigm. Ego depletion was indexed by comparing self-control performance in individuals who had previously performed an initial self-control act with individuals who had not. The first attempt to falsify ego-depletion theory compared three self-control conditions: high self-control, low self-control, and no selfcontrol (Baumeister et al., 1998). After the initial self-control manipulation, participants were instructed to solve an unsolvable puzzle. Consistent with ego-depletion theory, results showed that participants in the high self-control group withdrew from the puzzle task sooner than the participants in the other groups. However, despite a brief discussion, authors did not formulate specific propositions regarding ego-depletion mechanisms and components.

\subsubsection{Ego Depletion from a Resource Perspective, and from Alternative Perspectives}

After the first publication by Baumeister et al., researchers adopted a narrow perspective of ego depletion, by proposing that self-control exertion consumes a limited resource (Baumeister et al., 2000; Muraven \& Baumeister, 2000). Baumeister had used the metaphor that self-control resembles a muscle that gets tired after an initial effort (Baumeister et al., 2007), and initially, this approach was widely supported by empirical studies. However, few studies explored what this resource could be (Friese et al., 2019), and those who did were among the most controversial. Hence, the first critics emerged in 2010, questioning Gailliot, Baumeister, et al., (2007) and rejecting the hypothesis of glucose as a marker of self-control resources (Kurzban, 2010; Molden et al., 2012; Schimmack, 2012; Vadillo et al., 2016).

At the same time, a process model of ego depletion was proposed, which suggested that an initial act of self-control impairs subsequent self-control by reducing the motivation for control and the attention to the cues responsible for triggering such control, and by increasing the motivation to act based on impulses and the attention toward rewarding cues (Inzlicht \& Schmeichel, 2012). To our knowledge, only a single study found that motivation was significantly associated with an ego-depletion effect (Schmeichel et al., 2010), whereas other studies found no association (e.g., Boucher \& Kofos, 2012; Clarkson et al., 2010; Muraven et al., 2008; Vohs et al., 2021).

Another approach, the opportunity cost model, proposed that an initial self-control effort induces a redirection of computational processes (i.e., a priority shift) toward a task that optimizes costs and benefits (e.g., exit a self-control task), which could explain an apparently

\footnotetext{
${ }^{1}$ The relationship between individual differences in self-control (e.g., trait self-control) and situational differences in self-control (e.g., ego depletion) is not well articulated. Yet, meta-analyses and multi-lab replications showed trait self-control seems unrelated to ego-depletion (Dang et al., 2020; Dang, Liu, et al., 2017; Vohs et al., 2021), despite two studies that concluded it could be a moderator (DeWall et al., 2007; Gailliot, Schmeichel, et al., 2007).
} 
impaired subsequent self-control act (Kurzban et al., 2013). Finally, the "reinvention" of ego depletion theory (Lin et al., 2020) proposes that a subsequent self-control decrement is explained by disengagement from the necessity to control the self, which results in a reduced response caution rather than inhibition (Baumeister, 2014).

Although promising, these alternative perspectives have rarely been empirically supported and were often considered as merely competing theories (Baumeister, 2018; Baumeister \& Vohs, 2018).

\subsection{Ego Depletion Controversies}

\subsubsection{Meta-Analyses, Failed and Successful Replications}

In 2010, a meta-analysis concluded that the effect size of ego depletion was medium-tolarge $(\mathrm{d}=0.62$; Hagger et al., 2010). However, others noted that this meta-analysis relied on small-study effects and publication bias, and overestimated the aggregated effect size due to inappropriate corrections (Carter \& McCullough, 2013). This led the authors to the conclusion that ego-depletion effect size was not distinguishable from zero (Carter et al., 2015; see Friese et al., 2019, for a review of responses to these criticisms).

In an attempt to address this criticism, Hagger et al. (2016) conducted a multi-lab preregistered replication project, which included 2141 participants and independent tests of the phenomenon in the 23 participating labs. Results were consistent with a null effect of ego depletion "for the current paradigm" (Hagger et al., 2016, p. 556). This absence of effect was replicated in studies using frequentist statistics (e.g., Lurquin \& Miyake, 2017; Radel et al., 2019; Vadillo et al., 2018) and Bayesian statistics (e.g., Etherton et al., 2018; Vohs et al., 2021). One of the most recent multi-lab replication (Vohs et al., 2021, $\mathrm{k}=36, \mathrm{n}=3,531$ ) used a "paradigmatic replication approach", to overcome some limits of other multi-lab replications. Principal investigators recruited ego-depletion experts to develop the protocol and an advisory board with no involvement in past ego-depletion studies to develop preregistrations and statistical models. Finally, they randomly assigned one of two possible protocols to each lab. The first protocol used the letter-e task to induce ego depletion (i.e., participants had to cross out all "e" letters within a printed text), and persistence on unsolvable puzzles to measure it. The second protocol used a writing task to induce ego depletion (participants had to write a story with or without difficult instructions) and the Cognitive Estimation Test to measure it. Despite these efforts, Bayesian and frequentist analyses did not find evidence supporting ego depletion. To defend their replication failures, the authors claimed that replicability is not central to determine if a phenomenon exists or not (e.g., "ego depletion happens sometimes but not all the time" Baumeister, 2019), which conflicts with other studies stressing that a phenomenon is not reliable if not consistently replicated (e.g., Coles et al., 2018; Ioannidis, 2005; Open Science Collaboration, 2015).

Recently, a meta-analysis (Dang, Björklund, et al., 2017) showed a significant ego depletion effect on the capacity to remain focused on a goal. Another "updated" meta-analysis (Dang, 2018) showed that ego-depletion effect size was smaller than originally thought, but significant ( $\mathrm{g}=.38$, for all depletion tasks), especially when only "reliable depletion tasks were considered" ( $\mathrm{g}=.42)$. Another multi-lab replication study (Dang et al., 2020) found a small but significant ego-depletion effect $(\mathrm{d}=.16)$, especially among participants who had invested effort in the earlier depleting task. Finally, two high-powered studies supported ego depletion and 
suggested this phenomenon impairs attentional processes (Garrison et al., 2019; Lin et al., 2020).

\subsubsection{A Statistical-Power Issue}

Authors have argued that "if the true ego-depletion effect was zero, empirical studies should not consistently reveal null effects" (Friese et al., 2019, p. 9). If publication bias was the main reason for the significant ego depletion effects reported in the literature, as sometimes stated (e.g., Vadillo, 2019), there should be several significant reverse-depletion effects to support that ego depletion does not exist. If among 100 results, 50 turn out to be non-significant, it is tempting to think that the effect does not exist, but if the 50 remaining results show an effect in the same direction, that is unlikely to happen only by chance (Dienes, 2008). This pattern of results, observed in the ego-depletion literature (Friese et al., 2019), may instead highlight a statistical-power issue, fostered by the incorrect and overestimated effect size reported in the first meta-analysis (Hagger et al., 2010). Indeed, if 66 participants are required to detect an effect of $d=.62$ (Hagger et al., 2010), it would result in a power of $39 \%, 33 \%$, or $10 \%$ for an effect size of $\mathrm{g}=.42, \mathrm{~g}=.38$, or $\mathrm{d}=.16$, respectively. These effect sizes are those recently identified (Dang, 2018; Dang et al., 2020). In other words, with a sample size of 66 participants and updated effect sizes, the risk of finding a non-significant result even when the phenomenon exists would range from 61 to $90 \%$.

In sum, ego-depletion literature is heterogeneous and inconsistent. We argue that this does not necessarily demonstrate the nonexistence of the phenomenon, but may rather indicate the presence of theoretical and methodological limitations. The following sections describe and discuss these potential limitations.

\section{Theoretical Considerations: From Ego Depletion to Self-Control Fatigue as a Multicomponent Phenomenon}

Studies that have investigated the existence of ego depletion were often limited by their theoretical imprecision and by methodological issues that impaired the reliability of the results. Moreover, the term ego depletion may have been a misnomer. Originally, the word "ego" was chosen because it referred to the "part of the psyche that must deal with the reality of the external world" (Baumeister et al., 1998, p. 1253). The word "depletion" was then chosen to characterize the exhaustion of the ego. Nowadays, Freudian theories are less accepted as scientific than in the past, and ego often refers to a large set of self-identity constructs (e.g., Loevinger, 2014). To date, studies have focused on a reduction rather than a depletion (i.e., a total exhaustion) of self-control.

As stressed by some authors, the field of ego-depletion has been dominated by opposition and limitations for too long (Friese et al., 2019). We aim to provide a new theoretical model built on an integrative approach of ego-depletion perspectives. To be more accurate about the nature of the phenomenon, we propose to use new terminology. Thus, the term "self-control fatigue" will be preferred to "ego-depletion" as the latter is now often associated with the restrictive muscle metaphor, whereas "self-control fatigue" is meant to convey the multicomponent aspect of the phenomenon. The following sections, will clarify the components and processes underlying self-control fatigue, as well as their interactions, present the theoretical limitations of the ego-depletion literature, and describe the self-control fatigue theory. Then, we discuss methodological issues in the ego-depletion literature, and suggest 
empirical lines of research to disprove, update or support this theory. In these sections, "selfcontrol fatigue" will refer to our theoretical and empirical propositions, and "ego-depletion" will be used to discuss past studies.

\subsection{The Three Components of Self-Control Fatigue}

If we gather together the scattered and conflicting ego-depletion perspectives, and consider recent promising empirical results from the mental-fatigue literature (e.g., Mlynski et al., 2021), we can propose that self-control fatigue has three main components: self-control resources, selfcontrol willingness and self-control capacity. These components predict the ability to perform an initial self-control act. This initial act can temporarily affect each component, making it less efficient for a subsequent self-control act. Our self-control fatigue theory proposes that an initial self-control act induces temporary reductions in self-control resources, willingness and/or2 capacity (i.e., the three components), which lead to an impaired subsequent self-control act (i.e., the behavioral outcome). With this proposition, we formulate two hypotheses, (a) an initial selfcontrol act impairs a subsequent one; and (b) self-control components mediate the phenomenon. Accordingly, self-control fatigue theory is refuted if an initial self-control act does not lead to a reduced subsequent self-control act, or if the phenomenon does not rely on any of the aforementioned components. Figure 1 summarizes this original two-step process (inspired by Baumeister et al., 1998; Kotabe \& Hofmann, 2015).

\section{Self-Control Resources ${ }^{3}$}

These refer to the objective and subjective amounts of energy available for the self to initiate a self-control act (Clarkson et al., 2016; Kotabe \& Hofmann, 2015). These energetic markers could be psychological (e.g., captured by a self-reported questionnaire), such as perceived energy (e.g., Clarkson et al., 2010), perceived vitality (e.g., Rouse et al., 2013; Ryan \& Deci, 2008), perceived depletion (e.g., Baumeister et al., 1998; Clarkson et al., 2010, 2011, 2016; Francis et al., 2018; Mead et al., 2009; Vohs et al., 2021); or physiological, such as cardiac frequency, vagal activity, and beta-adrenergic activation (Laborde et al., 2018; Wright et al., 2019; Wright \& Mlynski, 2019).

\section{Self-Control Willingness ${ }^{3}$}

This is the volition or motivation to engage in a second self-control act (Inzlicht \& Schmeichel, 2012) or represents the priority of the self-control act (Kurzban et al., 2013). These concepts can be operationalized by the score on a questionnaire asking whether participants are motivated to engage in a self-control act (e.g., Muraven \& Slessareva, 2003; Vohs et al., 2013, 2021).

\section{Self-Control Capacity ${ }^{3}$}

This is the top-down mental process that makes the self-control act possible (e.g., executive functions; Hofmann, Schmeichel et al., 2012). The authors proposed that working memory,

\footnotetext{
${ }^{2}$ Yet, it is difficult to conclude whether these three components are all involved in self-control fatigue. See section "Determining components independencies and their role in self-control fatigue" for a discussion and perspectives.
}

${ }^{3}$ Self-control resources, willingness, and capacity are at the cognitive level of analysis. The self-control act is the outcome at the behavioral level of analysis (Friese et al., 2019). 
inhibition, and cognitive flexibility represent self-control capacity (Hofmann et al., 2014; Hofmann, Schmeichel, et al., 2012; Pfeffer \& Strobach, 2017). Operationalizing these concepts can be done through behavioral markers such as reaction time and errors in cognitive tasks (Baumeister et al., 1998; Dang, 2018; Hagger et al., 2010; Muraven \& Slessareva, 2003) and brain activity can be analyzed using neuroimaging techniques such as electroencephalography (e.g., Inzlicht \& Gutsell, 2007; Wang \& Yang, 2014) or functional magnetic resonance imaging (e.g., Berkman \& Miller-Ziegler, 2013; Hedgcock et al., 2012).

\section{Self-Control Act ${ }^{3}$}

Self-control act refers to the behavioral implementation of the self-control capacity (Kotabe \& Hofmann, 2015) that aims to resolve a motivational conflict (de Ridder et al., 2018; Fujita, 2011; Gillebaart, 2018). The operationalization of this concept is measured by temptation yielding (Baumeister et al., 1998; Friese et al., 2015; Sellahewa \& Mullan, 2015), as well as physical or cognitive performance maintenance or success on self-control tasks.

Some ego-depletion articles have suggested that particular components should be rejected, e.g., "self-control depletion is not some mysterious result of lost self-control resources but rather the result of shifts in motivation" (Inzlicht \& Schmeichel, 2012, p. 452). Over the years, ego depletion has been observed mainly through one marker (i.e., the self-control act), with a hypothesis related to the decrease of a single component (i.e., the self-control resource). We contend for two main reasons that this narrow characterization of ego depletion should be updated into a more comprehensive definition of self-control fatigue (e.g., de Ridder et al., 2018; Hirt et al., 2016; Kotabe \& Hofmann, 2015) including the three aforementioned components. Firstly, ego-depletion literature never addressed empirically the relative weight of these components in the process of self-control fatigue. Therefore, each of these components may be sufficient for its emergence. It follows that discarding the existence of one of the components cannot fully discard the existence of self-control fatigue. Secondly, these components seem theoretically interconnected, which weakens their isolation based on theoretical argument.

To clarify which processes are involved in self-control fatigue, the main ego-depletion literature limitations (i.e., a too narrow approach to the phenomenon) need to be overcome and self-control fatigue should be investigated as a multicomponent phenomenon. Based on this theoretical shift, empirical studies could focus on evaluating the relative weight of these components and their interaction. In sum, overlooking the multicomponent nature of selfcontrol fatigue may have resulted in a limited understanding and undue rejection of the egodepletion theory.

\section{Figure 1. Two-step process of the multicomponent self-control fatigue phenomenon}




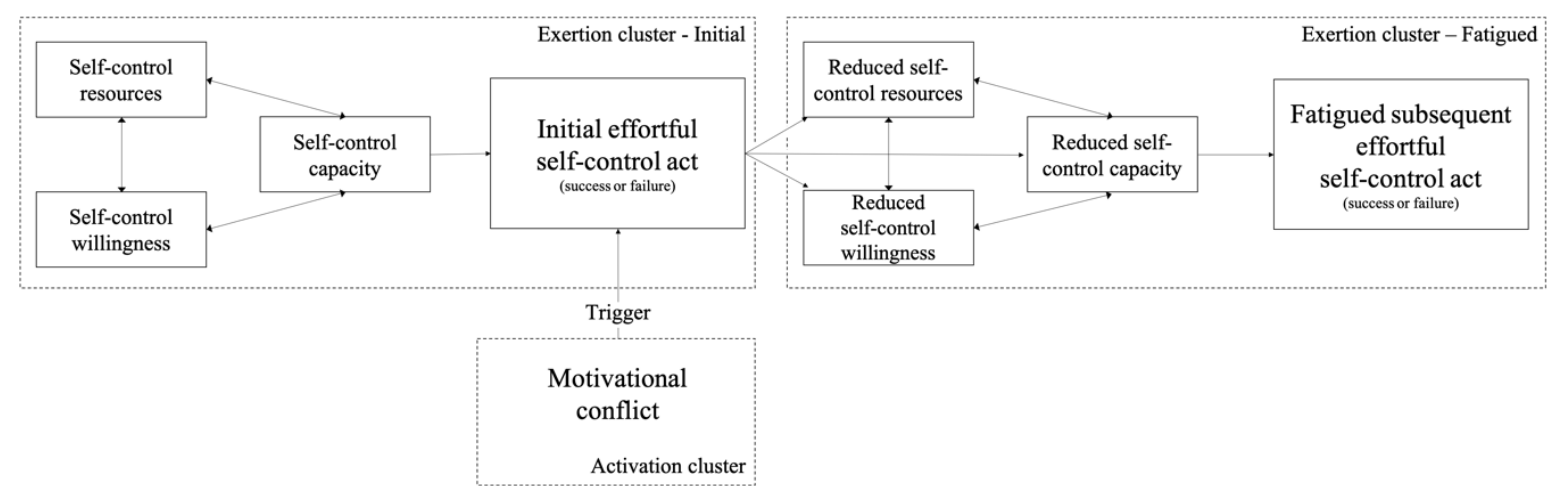

Note. This figure is inspired from the integrative self-control model by Kotabe \& Hofmann, (2015) and applies this model to self-control fatigue. Self-control fatigue is the temporary reduction or shift of self-control resources, willingness and/or capacity resulting from an initial effortful self-control act and impairing a subsequent effortful self-control act. Self-control resources are the objective and subjective amount of energy available for the self to initiate a self-control act. Self-control willingness is the volition or motivation to engage in a second selfcontrol act. Self-control capacity is the cognitive top-down mental processes (e.g., executive functions) making the self-control act possible. A self-control act is the act of self-control itself, which could be successful or unsuccessful. The double arrows suggest self-control resources, willingness, and capacity are correlated. Recently, authors have proposed that self-control effort and perceived difficulty are additional components that predict the act of self-control. However, because these potential components have not been supported by empirical evidence, they are not included in this figure.

\subsubsection{Determining Components Independencies and Their Role in Self-Control Fatigue}

Currently, it is difficult to estimate whether the three components of self-control fatigue and the outcome are independent. For example, one may argue that self-control resources and selfcontrol willingness are so thinly interconnected theoretically that they could refer to a single construct. First, if the authors assumed that the concept of resources has to be preferred to the concept of willingness (Inzlicht \& Schmeichel, 2012), or vice versa (e.g., Baumeister \& Vohs, 2007), it seems reasonable to assume that they are distinct. Then, theoretical propositions such as the integrative model of self-control (Kotabe \& Hofmann, 2015), which aims to identify predictors of a self-control act, stated that self-control capacity, self-control motivation and self-control act are distinct components, independent but correlated.

At the empirical level, one study showed that self-control capacity (e.g., inhibition) was affected by a previous self-control act, suggesting that self-control capacity and self-control act are distinct, although the strength of their association remains unknown (Christiansen et al., 2012). Similarly, other authors showed that if self-control resources are increased for egodepleted individuals, ego depletion could be counteracted, suggesting self-control resources and willingness are distinct predictors of a self-control act (Muraven \& Slessareva, 2003). Recently, a study jointly assessed self-control capacity (i.e., inhibition) and self-control resources (i.e., perceived fatigue; Lin et al., 2020); and another jointly assessed self-control resources (i.e., perceived fatigue) and self-control willingness (i.e., perceived motivation; Vohs et al., 2021). Our reanalysis of these datasets revealed that self-control capacity and resources were significantly and negatively related, but with a small effect size $(r=-.03, p<.001)$. Similarly, self-control resources were significantly and positively correlated with self-control 
willingness, but also with a small effect size $(\mathrm{r}=.13, \mathrm{p}=<.001)$, which reveals a small amount of shared variance (i.e., a small overlapping, $0.01 \%$ and $1.69 \%$ respectively; see Supplementary Material 1). This preliminary evidence provides support for the assumption that the three components of self-control fatigue are distinct, but future self-control fatigue research should clarify this point.

Through the multicomponent approach, future studies could go beyond current debates that focus on which single component produces the depletion effect. Studies could consider the three components together to statistically investigate (a) the extent to which they are interconnected (e.g., correlation coefficients and shared variance); (b) whether their concurrent shifts produce the self-control fatigue effect (e.g., identify significant relations between all shifts or only one shift, and the subsequent self-control act, through regression); (c) the extent to which these shifts explain the phenomenon (e.g., explained variance comparisons between resources shift and willingness shift, through regression); and (d) whether one component could be rejected in favor of another because it is ineffective or weak (e.g., effect size comparisons between resources shift and willingness shift, through regression, null effect of resources shift when considering motivation shift through equivalence tests).

\subsection{Self-Control Fatigue Theory from a Lakatosian Perspective}

Rejecting a hypothesis is different from rejecting a theory. Statistical tests provide evidence in favor of one hypothesis or another, based on data. However, results favoring or rejecting a hypothesis do not inform about the veracity of a theory. Ego-depletion theory has been tested and rejected solely based on statistical evidence against a particular hypothesis (e.g., Schimmack, 2016; Vohs et al., 2021). We propose to go further and to estimate the level of confidence that could be assigned to self-control fatigue theory through the Lakatosian approach and the systematic replications framework (Dienes, 2008; Lakatos, 1978; Uygun Tunç \& Tunç, 2020, for reviews). In their method, the authors differentiate the core assumptions of a theory from auxiliary hypotheses. The core assumptions refer to the concepts. The auxiliary hypotheses represent refutable operationalizations of these abstract concepts. Accordingly, the three self-control fatigue components are the core assumptions of the theory and their operationalizations correspond to the refutable auxiliary hypotheses that can be tested. To measure theory veracity, the authors propose that researchers should accumulate evidence from direct replications (i.e., replications based on similar operationalizations) and from conceptual replications (i.e., replications based on different operationalizations). Only the accumulation of evidence related to different auxiliary assumptions (i.e., different operationalizations) of each core theoretical assumption will elucidate the veracity of the theory as a whole. Figure 2 illustrates a Lakatosian perspective of the self-control fatigue theory, based on the ego-depletion literature. 


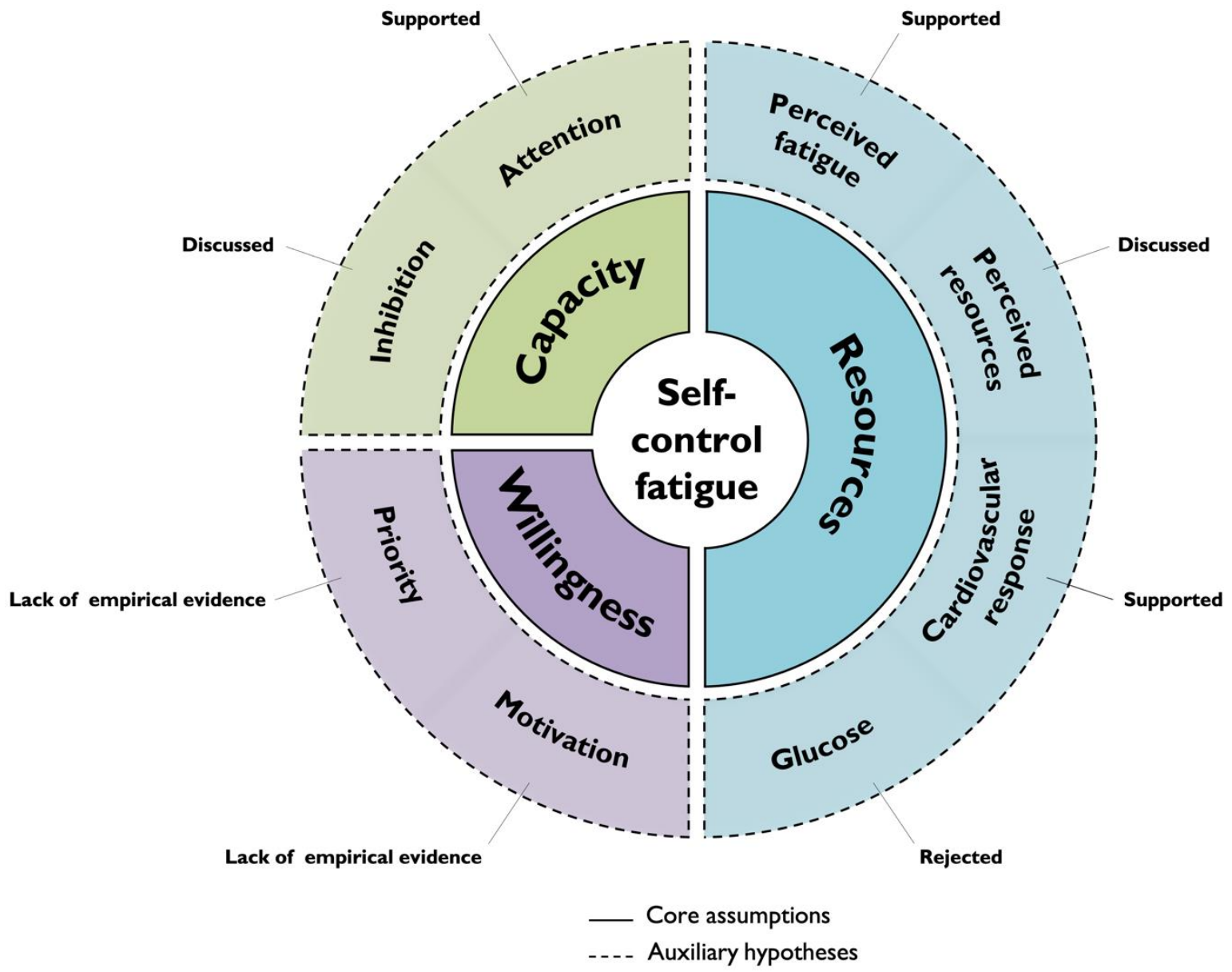

Figure 2. A Lakatosian perspective of the self-control fatigue theory, with its core assumptions and auxiliary hypotheses

Note. In the literature, perceived fatigue and perceived resources have mainly been assessed based on self-reported measures; cardiovascular response and glucose have mainly been assessed based on physiological measures; inhibition and attention have mainly been assessed based on behavioral markers (e.g., reaction time, accuracy), and inhibition has also been assessed based on neuroimaging markers. This figure is an epistemological representation of the literature. For information regarding core assumptions and auxiliary hypotheses interactions, see Figure 1. The conclusion regarding the current state of the literature (i.e., "discussed", "supported" or "lack of empirical evidence") are based on the literature.

\subsection{Theoretical Considerations for Future Self-Control Fatigue Research}

Rejections of ego-depletion core assumptions and theory were based on rejections of isolated auxiliary hypotheses related to isolated core assumptions, contrary to recommendations (Dienes, 2008; Uygun Tunç \& Tunç, 2020). For example, the glucose model rejection, an auxiliary hypothesis of the core assumption of self-control resources, led to the rejection of both the resources' core assumption (e.g., Inzlicht \& Schmeichel, 2012), and the whole theory (e.g., Schimmack, 2016). Self-control fatigue studies need to overcome this systemic ego-depletion limitation by exploring a variety of auxiliary hypotheses, to draw reliable conclusions about the core assumptions and the entire theory. Table 1 summarizes the theoretical limits of ego-depletion literature, and the proposed perspectives for self-control fatigue research. 
FROM EGO DEPLETION TO SELF-CONTROL FATIGUE

Table 1. Theoretical considerations for future self-control fatigue research

\begin{tabular}{|c|c|c|}
\hline $\begin{array}{l}\text { Core } \\
\text { assumptions } \\
\text { (i.e., the } \\
\text { components) }\end{array}$ & Theoretical limits of the ego-depletion literature & $\begin{array}{l}\text { Theoretical perspectives for self-control fatigue } \\
\text { studies }\end{array}$ \\
\hline $\begin{array}{l}\text { Self-control } \\
\text { capacity }\end{array}$ & $\begin{array}{l}\text { - Used to draw conclusions about the whole theory. } \\
\text { - Focused on a particular auxiliary hypothesis related to a single core } \\
\text { assumption of the theory. } \\
\text { - Dominated by behavioral studies that tested whether self-control capacity } \\
\text { or the self-control act is different between individuals who performed an } \\
\text { initial depleting task and individuals who did not. } \\
\text { - Often mixed results, depending on the auxiliary hypotheses considered } \\
\text { (e.g., behavioral markers versus neural markers, Wang \& Yang, 2014). } \\
\text { - Often confuses between the capacity for self-control (i.e., the process) and } \\
\text { the self-control act (i.e., the behavior) (e.g., Hagger et al., 2016). }\end{array}$ & $\begin{array}{l}\text { - Test a variety of auxiliary hypotheses to draw } \\
\text { reliable conclusions about the role of this } \\
\text { component. } \\
\text { - Theoretically distinguish the three core assumptions } \\
\text { (i.e., the three components) from the outcome of the } \\
\text { processes (i.e., the reductions) }\end{array}$ \\
\hline $\begin{array}{l}\text { Self-control } \\
\text { resources }\end{array}$ & $\begin{array}{l}\text { Rejects the role within the phenomenon of self-control resources (i.e., the } \\
\text { core assumption) on the phenomenon (e.g., Inzlicht \& Schmeichel, 2012) } \\
\text { and the entire ego-depletion theory (e.g., Schimmack, 2016; Vadillo, } \\
\text { 2019) based on the rejection of the glucose model (i.e., a single auxiliary } \\
\text { hypothesis). }\end{array}$ & $\begin{array}{l}\text { - Investigate other auxiliary hypotheses, such as } \\
\text { perceived energy, perceived vitality, and } \\
\text { cardiovascular responses, to inform this core } \\
\text { assumption. }\end{array}$ \\
\hline $\begin{array}{l}\text { Self-control } \\
\text { willingness }\end{array}$ & $\begin{array}{l}\text { - Core assumption that received the least consideration. } \\
\text { - Supported almost exclusively by theoretical propositions (e.g., motivation } \\
\text { shift model, Inzlicht \& Schmeichel, 2012; priority shift model, Kurzban et } \\
\text { al., 2013) that have not been empirically tested. }\end{array}$ & $\begin{array}{l}\text { - Investigate the role of this core assumption on the } \\
\text { self-control fatigue phenomenon. } \\
\text { - Investigate a variety of auxiliary hypotheses related } \\
\text { to self-control willingness (i.e., a variety of } \\
\text { operationalizations, such as motivation, priority). }\end{array}$ \\
\hline
\end{tabular}


In sum, some auxiliary hypotheses have been rejected, which suggests that ego-depletion theory might be false. However, multiple auxiliary hypotheses pertaining to different core assumptions have not been investigated, or have been insufficiently investigated. To move forward and conclude that self-control fatigue is a multicomponent phenomenon, a more comprehensive investigation of these auxiliary hypotheses is required. Moreover, because of methodological limitations, some ego-depletion studies could not be considered as tests of the phenomenon (e.g., Dang, 2016; de Ridder et al., 2018; Friese et al., 2019; Lurquin \& Miyake, 2017).

\section{Methodological Limitations of Ego-Depletion Literature that Self-Control Fatigue Studies Must Overcome, and Potential Solutions}

\subsection{Limitation 1: The Need for Accurate, Comprehensive, and Refutable Definitions}

Over the years, ego depletion definition deviated from Baumeister's original version, which referred to a temporary reduction in the self's capacity to engage in a self-control act, due to a prior self-control act (Baumeister et al., 1998). For example, Lin et al. (2020) defined ego depletion as feeling tired after a mental effort. Other referred to deficits in persistence and performance on cognitive and motor tasks after a self-regulatory effort (Segerstrom \& Nes, 2007), or to impaired performance after any behavior's monitoring and modification (Vohs et al., 2005). Inaccurate definitions contributed to inaccurate conclusions that increased the confusion in the ego-depletion literature. This confusion also originated from a multitude of definitions of self-control (see Gillebaart, 2018, for a review), which has increased the likelihood of results that are invalid and lack replicability (Ioannidis, 2005). Moreover, definitions such as "monitoring and modifying behavior" to define self-control (Vohs et al., 2005) or "feeling depleted" or "a state where mental resources for self-regulation are minimal" to define ego depletion (Unger \& Stahlberg, 2011; Wolff et al., 2013), are so vague that they are almost impossible to falsify, making the related theories "bad theories" (Popper, 1935).

\subsubsection{Perspective 1: Acknowledging the Importance of Self-Control, Effortful Strategies, and Motivational Conflict in the Definition of Self-Control Fatigue}

In line with previous work (e.g., Lurquin \& Miyake, 2017), we contend that accurate, comprehensive, and falsifiable definitions of self-control and self-control fatigue are required for replicable self-control fatigue research. We consider that a consensus needs to be reached for defining self-control as the self-regulation process by which an individual resolves a motivational conflict through either an effortless or effortful strategy (Fujita, 2011; Gillebaart, 2018; Milyavskaya et al., 2019). According to this definition, self-control operates only for conflict resolution, not for other regulatory processes such as goal setting. Effortless selfcontrol strategies are automatic and do not require self-control resources or willingness (e.g., asymmetric cognitive associations, Fishbach et al., 2003). Thus, they are not related to the selfcontrol fatigue phenomenon and will not be discussed further. Effortful self-control strategies are reflective and rely on self-control resources and willingness (e.g., temptation avoidance, Ent et al., 2015; temptation reappraisals, Fujita \& Han, 2009; effortful inhibition, Muraven \& Baumeister, 2000), and are thus the only strategies that could induce self-control fatigue. This definition of self-control is specific, falsifiable, and focuses on situational conflict resolution strategies (i.e., in-situ states of self-control), unlike definitions based on general tendencies (i.e., trait self-control). Since ego depletion was considered to be a state rather than a trait of impaired self-control, we argue that it is appropriate to use a state definition of self-control to approach 
self-control fatigue. This could improve future research designs because it does not conflate two constructs that have similarities but are nevertheless different (for a review, see de Ridder et al., 2018). Finally, this updated definition stresses that several effortful self-control strategies exist and that only effortful strategies can induce self-control fatigue. Based on this definition, different effortful self-control strategies might induce self-control fatigue, such as temptation inhibition and temptation avoidance. Moreover, this definition could help task selection by considering whether a task requires an effortful self-control strategy or an effortless one, the latter making self-control fatigue unlikely.

Based on the above recommendations, we define self-control fatigue as a temporary impaired effortful self-control act caused by an initial effortful self-control act that aimed to resolve a motivational conflict and decreased self-control resources, willingness and/or capacity (Figure 1). Several studies initially intended to investigate ego depletion are not within the scope of this definition. For example, some studies manipulated mental or cognitive effort (e.g., Englert et al., 2015; Lin et al., 2020), whereas this type of effort does not necessarily include self-control fatigue components. Others used tasks unrelated to self-control or conflict resolution, which are essential for ego-depletion investigation (e.g., Finkel et al., 2006). As such, these studies may not have actually tested ego depletion (Lurquin \& Miyake, 2017). We argue that rigorous empirical studies based on this specific and falsifiable definition of selfcontrol fatigue are required to test the phenomenon.

To our knowledge, no ego-depletion study, even ambitious projects such as the recent multilab replications (Dang et al., 2020; Hagger et al., 2016; Vohs et al., 2021), considered this updated and falsifiable definition of self-control. Instead they considered self-control to be "the extent to which an individual can override a dominant response in favor of an alternative, more effortful course of action" (Hagger et al., 2016, p. 547) or "alter a predominant response tendency, control impulses, and engage in volitional behavior" (Vohs et al., 2021, p. 3 of the preprint version). As stressed by several authors (e.g., de Ridder et al., 2018; Duckworth et al., 2018; Fujita, 2011; Gillebaart, 2018), these definitions are too narrow, overlap with definitions of inhibition (Diamond, 2013), and ignore an important aspect of self-control: the motivationalconflict resolution.

Similarly, inaccurate definitions of self-control have contributed to the unclear definition of ego-depletion. For example, definitions such as "using self-control on an initial task renders subsequent self-control less successful than if not deployed earlier" (Vohs et al., 2021) does not permit an accurate understanding of the processes involved, or the ability to falsify them. Such limitations have weakened the validity of results of ego-depletion studies and should be overcome in the future. We recommend adopting the more accurate and up-to-date definition of self-control proposed in the recent literature, which stresses effortful self-control strategies. Finally, if researchers are interested in inducing self-control fatigue, we recommend ignoring effortless self-control strategies that are not supposed to trigger this phenomenon.

\subsection{Limitation 2: The Need for a Clear Distinction Between Self-Control Fatigue, Cognitive Effort, and Mental Fatigue}

The original assumption of ego-depletion theory was that an effortful self-control act induces self-control impairment (Baumeister et al., 1998; Lurquin \& Miyake, 2017). Some 
studies drifted away from this original assumption and stated that ego depletion means to "feel tired or depleted after exerting mental effort" (e.g., Lin et al., 2020, p. 1). However, as assumptions have changed, accuracy and falsifiability may have been lost in the process. This statement implies that any task requiring cognitive effort produces ego depletion, which may not be the case when two different concepts are merged: ego depletion and mental fatigue. A meta-analysis suggested that this semantic merger was not problematic and concluded that ego depletion and mental-fatigue tasks produce similar effects on subsequent tasks (Giboin \& Wolff, 2019). Yet, we contend that this conclusion should be treated cautiously for at least four reasons. First, half of the ego-depletion studies considered in the meta-analysis were based on tasks such as labyrinth, arithmetic, and mental-imagery tasks, which have been criticized due to their lack of sensitivity in capturing the ego-depletion phenomenon (Dang, 2018; Lurquin \& Miyake, 2017, and see "Limitation 3" below). Second, studies unrelated to physical endurance performance were excluded, which limits the generalization of the conclusions to other domains of physical performance. Third, the effects in the ego-depletion task and the mental-fatigue task were interpreted as being similar based on a non-significant correlation. Yet, the absence of significance is not evidence of the absence of effect (Harms \& Lakens, 2018). Fourth, recent results showed that a longer initial depletion task induced greater detrimental effects on a subsequent physical task (Boat et al., 2020). These results are not congruent with the results of Giboin \& Wolff (2018) that showed no evidence of an effect of duration, which was shorter in the ego-depletion task compared to the mental-fatigue task.

In sum, empirical evidence is insufficient to conclude that ego depletion and mental fatigue are a single phenomenon.

\subsubsection{Perspective 2: Conceptualizing Self-Control Fatigue as a Specific Type of Mental Fatigue}

Mental fatigue is the feeling of tiredness or exhaustion resulting from short (e.g., minutes, O'Keeffe et al., 2020; Smith et al., 2019; Wright et al., 2013) or long (e.g., hours, Marcora et al., 2009; Van Cutsem et al., 2017) periods of cognitive activity. It is associated with tiredness, an aversion to continue the present activity, and impaired cognitive or behavioral performance (Boksem \& Tops, 2008). Mental fatigue is different from self-control fatigue (see Perspective 1). Specifically, any type of cognitive activity can induce mental fatigue (e.g., memory task, Cook et al., 2007; arithmetic task, Gergelyfi et al., 2015; puzzle task, Van der Linden et al., 2003), whereas self-control fatigue is induced only by an effortful self-control act aiming to resolve a motivational conflict. While these phenomena share similarities, such as tiredness (reduced self-control resources), aversion to continue (reduced self-control willingness), or impaired performance (reduced self-control capacity), self-control fatigue should be considered as a type of mental fatigue specific to self-control and motivational conflict resolution. This distinction between mental fatigue and self-control fatigue could clarify whether previous studies should be included in the self-control fatigue literature and improve the exclusion criteria for future meta-analyses. Moreover, this distinction could improve the accuracy of future study designs by focusing on the resolution of a motivational conflict through an effortful self-control act.

\subsection{Limitation 3: The Need for Triggering Effortful Strategies to Resolve a Motivational Conflict}


In the ego-depletion literature, depleting and measurement tasks were often chosen without strong theoretical or empirical justification, but rather because, for example, they "have been used in the depletion literature" (Vohs et al., 2021, p. 5). Such a task identification procedure has poor scientific value and does not ensure that it actually activates the processes thought to solicit, exhaust, or capture the phenomenon of ego depletion. Often, "inappropriate depleting tasks" (Dang, 2018, p. 646) were chosen "regardless of whether they could be considered as a valid operationalization of self-control" (Carter et al., 2015, p. 15). Frequently, the tasks were "mentally demanding, requiring effort, or simply being difficult", but it is difficult to "unambiguously determine whether or not [they] implicate self-control, and determine whether one should expect a significant ego-depletion effect" (Lurquin \& Miyake, 2017, p. 2). For example, in the multi-lab replication by Hagger et al. (2016), the task "did not involve selfregulation" (Baumeister \& Vohs, 2016; see Drummond \& Philipp, 2017 for criticisms regarding this paper). Accordingly, caution should be taken when considering letter-cancellation tasks, as they "may not be a suitable inducer of ego depletion" (Wimmer et al., 2019, p. 345), "have not been independently validated as effective measures of self-control" (Lurquin \& Miyake, 2017, p. 2), and failed (through frequentist and Bayesian statistics) to induce ego depletion in two multi-lab studies (Hagger et al., 2016; Vohs et al., 2021).

Moreover, such task selection procedures could perpetuate tasks with low validity and reliability. For example, the letter-e task showed inefficiency across two multi-lab studies (Hagger et al., 2016; Vohs et al., 2021) despite criticism in the past. Specifically, the authors considered that "the e-crossing task is generally considered not "depleting," thus questioning its effectiveness" (Dang, 2016, p. 1). To date, and despite empirical evidence against it, especially against its electronic versions, letter-cancellation tasks have been supported only by theoretical arguments (e.g., Hagger \& Chatzisarantis, 2016), but there is still no strong empirical evidence supporting an association between performance in such tasks and any aspect of self-control. As such, using a task only because it has been used in past research may lead to a waste of resources ( $\mathrm{k}_{\text {total }}=59, \mathrm{~N}_{\text {total }}=5,672$ in the case of the letter-e task). Other examples of questionable tasks exist (e.g., symbol-counting tasks, Lin et al., 2020; labyrinth tasks, Martijn et al., 2007), and we hope the discussion proposed here could help researchers to better identify them.

Finally, from a replicability perspective, task selection based on use in the past accumulates direct replications that inform about procedure (un)reliability, instead of conceptual replications, that inform about theory reliability (Crandall \& Sherman, 2016).

According to the integrative model of self-control (Kotabe \& Hofmann, 2015), commonly used tasks may be suboptimal for three reasons to induce a motivational conflict resolved by a self-control act. This model proposes that three distinct motivations are involved in a selfcontrol act: the desire (e.g., immediate motivation to think about a white bear or to eat a sweet cake) and the higher-order goal (e.g., motivation to perform well at a task or to eat healthy), which are in the activation cluster and induce a motivational conflict; and the self-control motivation (i.e., motivation to perform a self-control act to resolve the motivational conflict), which is in the exertion cluster.

First, authors (Baumeister et al., 1998; Kotabe \& Hofmann, 2015) have stressed that the stronger the desire, the stronger the motivational conflict, and thus, the more effortful the selfcontrol act. However, most studies operationalized desire with neutral stimuli such as a letter 
to not cross (e.g., letter "e" if followed by a vowel, Hagger et al., 2010, 2016). Other studies aimed to trigger a motivational conflict with a neutral inducer such as tedious tasks causing a desire to stop persisting (Finkel et al., 2006). Designs based on neutral stimuli and neutral desire inducers could call into question whether participants truly experienced a desire or not. To our knowledge, no studies assessed participants' desire (e.g., no study asked participants the extent to which they desired to cross out the letters "e" or would prefer to quit the task). Additionally, if these "neutral" designs induced a desire, we could question their validity. For example, is a desire triggered by a neutral inducer desirable enough to activate an effortful self-control act compared to a desire triggered by an effective inducer? This question is important because most ego-depletion studies, including famous replication failures (e.g., Hagger et al., 2016; Vohs et al., 2021) did use neutral inducers.

Secondly, in the integrative self-control model, the higher-order goal that promotes a conflict is "pursued intentionally and associated with declarative expectations of long-term benefits" (Kotabe \& Hofmann, 2015, p. 619). Moreover, studies stressed that autonomous goals, which are important for the self (e.g., want-to motivation), were associated more with effortful self-control acts than with controlled goals, which are not important for the self (haveto motivation) (Converse et al., 2019; Milyavskaya et al., 2015). Finally, studies on self-control excluded participants who did not report a goal that was important to them. They considered that desires proposed would not be conflictual, thus individuals might not develop a self-control act (e.g., participants who considered healthy diet or physical activity as not really important for them, Cheval et al., 2017; Fishbach et al., 2003). Despite the importance of a higher-order goal for motivational conflict and effortful self-control, ego-depletion studies usually do not consider what type of goal is endorsed by participants. If an individual experiences a desire that does not threaten a goal important for the self, an effortful self-control act may be unlikely, making self-control fatigue potentially unlikely to occur.

Thirdly, most ego-depletion studies assumed that participants endorsed a high self-control motivation and persisted throughout the depleting tasks with the highest performance possible. Except for rare studies (e.g., Vohs et al., 2021), most research did not assess self-control motivation to verify this statement. Moreover, to our knowledge, no study investigated whether individuals truly persisted during the depleting tasks. Common manipulation checks include perceptions such as fatigue, difficulty, effort, or frustration (e.g., Dang et al., 2020; Hagger et al., 2016; Vohs et al., 2021) but not performance during the depleting tasks. Without information on self-control motivation, and the persistence of effortful self-control during the depleting tasks, it could be tricky to estimate whether ego depletion was likely or not. These factors should be controlled for in future studies.

Taken together, these limitations may have unduly contributed to reject the existence of the ego depletion phenomenon.

\subsubsection{Perspective 3.1: Pre-tests}

To improve the validity of self-control fatigue task selection, we encourage the implementation of pre-tests. Some studies have already proposed solutions to improve task validity, such as using executive-function tasks (Duckworth \& Kern, 2011) because executive functions are associated with self-control (see Hofmann, Schmeichel, et al., 2012, for a review). While this first step toward choosing valid self-control fatigue tasks is important, it may not be sufficient. 
To ensure that the tasks trigger an effortful self-control act to resolve a motivational conflict, we propose three approaches. The first could be to compare the performance on the task to be validated, using metrics such as reaction time, accuracy or errors, with self-control correlates such as the trait self-control scale (Tangney et al., 2004), the temptation-avoidance scale (Ent et al., 2015), or the effortful control scale (Atherton et al., 2020). The second could be to investigate whether performance in the tested task is associated with self-reported measures of self-control in daily life. For example, performance on a Stroop task is related to perceived resistance (Hofmann et al., 2014), which is a self-control act resolving motivational conflict in daily life (e.g., Hofmann, Baumeister, et al., 2012; Ozaki et al., 2017). A third approach could be to investigate whether performance in the tested task is associated with performance in conflict-resolution cognitive tasks. For example, the mouse-tracking technique has been used to activate a motivational conflict and test its resolution, which has been shown to be related to self-control (Georgii et al., 2020; Stillman et al., 2018). Such preliminary validation approaches could further improve the reliability of self-control fatigue studies.

\subsubsection{Perspective 3.2: Assessing the Affective Charge of the Tasks, Among Individuals with Higher-Order Goals}

According to the literature, affectively charged stimuli could increase the motivational conflict, by increasing the desire strength because of the innate motivation they carry (e.g., automatic approach-avoidance tendencies; Kemps et al., 2013; Krieglmeyer \& Deutsch, 2010). Studies based on affective executive-function tasks (i.e., with affectively charged stimuli) have shown that cognitive processes related to the self-control capacity (e.g., attention, inhibition) are influenced by affective stimuli. For example, stimuli associated with high-calorie food stimuli or sedentary stimuli induced slower reaction time, less attention bias, poorer inhibition, and a higher recruitment of inhibition processes than when associated with low-calorie food stimuli or physical activity stimuli (Carbine et al., 2017; Cheval et al., 2020, 2021; Mas et al., 2019, 2020). Accordingly, affectively charged inducers seem more likely than neutral inducers to bring about a motivational conflict, and thus, to trigger an effortful self-control act to override the default response, potentially inducing self-control fatigue. To this day, the only empirical evidence supporting the notion that affective stimuli induce stronger self-control fatigue comes from a meta-analysis showing that depleting affectively-charged tasks (i.e., food-temptation task) induced the highest effect size $(\mathrm{d}=.63$; Dang, 2018), but was associated with high heterogeneity (95\% CI [0.29, 0.98], I2=63.09). The effect of affectively-charged stimuli should be investigated in the future through validated self-control tasks (e.g., pre-tested affective executive-function tasks). This research line comparing the effect of affectively-charged stimuli to that of neutral stimuli could be initiated based on validated affective executive-function tasks such as the emotional stop-signal task (Pawliczek et al., 2013), the affective set-shifting task (Mobbs et al., 2008), or the affective go/no-go task (e.g., Carbine et al., 2017).

Because ego-depletion studies usually triggered a conflict with no higher-order goal, or goals that were not important for the self, they could have induced a cognitive conflict (i.e., a conflict between two cognitive processes) rather than a motivational conflict (i.e., a conflict between two motivations; Fillmore \& Vogel-Sprott, 2000). The tasks used in these studies could have therefore not have required self-control. Future studies should consider what higher-order goal is threatened during the fatiguing task, and include participants who report a higher-order goal important for them, as some self-control studies did (e.g., Fishbach et al., 2003). For 
example, researchers could include only participants with a higher-order goal toward a healthy diet, and threaten this goal with affective executive-function tasks depicting unhealthy food (e.g., affective go/no-go with "go" stimuli associated with pictures of healthy food, and "nogo" stimuli associated with pictures of unhealthy food).

Finally, self-control fatigue studies could assess participants' self-control motivation during or right after the fatiguing task to investigate whether performance during the fatiguing task (i.e., a persistence marker) is associated with self-control fatigue in the subsequent task. To our knowledge, few studies have investigated self-control motivation to perform a self-control act (e.g., Vohs et al., 2021) or tested if self-control during the initial task and its potential decline is related to self-control in the subsequent task. For example, future self-control fatigue studies could assess self-control motivation continuously (e.g., each minute) during the fatiguing task to estimate whether individuals remain motivated for the effortful self-control act or not, and could investigate the extent to which persistence markers of the effortful self-control act during the fatiguing task (e.g., error-rate evolution) are related to self-control fatigue on the subsequent task4. Table 2 summarizes the methodological limitation of the ego-depletion literature, and the perspectives for self-control fatigue research. 
Table 2. Summary of the practical limitations of the ego-depletion literature and perspectives for self-control fatigue research

\begin{tabular}{|c|c|}
\hline Practical limitations of the ego-depletion literature & Perspectives for self-control fatigue research \\
\hline $\begin{array}{l}\text { Limitation 1: The need for accurate, comprehensive, and } \\
\text { falsifiable definitions } \\
\text { - Ego-depletion definitions are often vague. } \\
\text { - These definitions often disregard the importance of } \\
\text { effortful self-control strategies and motivational } \\
\text { conflict. }\end{array}$ & $\begin{array}{l}\text { Perspective 1: Acknowledging self-control, effortful self-control strategies, and } \\
\text { motivational conflict to define self-control fatigue } \\
\text { - Define self-control fatigue as a temporary-impaired act of self-control } \\
\text { caused by an initial effortful self-control act that aimed to resolve a } \\
\text { motivational conflict and that decreased self-control resources, } \\
\text { willingness, and/or capacity. }\end{array}$ \\
\hline $\begin{array}{l}\text { Limitation 2: The need for a clear distinction between self- } \\
\text { control fatigue, cognitive effort, and mental fatigue } \\
\text { - Ego depletion is often confused with mental fatigue. }\end{array}$ & $\begin{array}{l}\text { Perspective 2: Conceptualizing self-control fatigue as a specific type of mental } \\
\text { fatigue } \\
\text { - Self-control fatigue is specific to motivational conflict resolution and } \\
\text { could be induced by an initial self-control act aiming to resolve such } \\
\text { conflict. }\end{array}$ \\
\hline \multirow{2}{*}{$\begin{array}{l}\text { Limitation 3: The need for triggering effortful strategies to } \\
\text { resolve a motivational conflict and observe ego depletion } \\
\text { - The theoretical rationale underlying ego-depletion task } \\
\text { selection is often insufficient. } \\
\text { - Ego-depletion studies often ignore, and never controlled } \\
\text { for, the two components of a motivational conflict (i.e., } \\
\text { desire, higher-order goal important for the self) and the } \\
\text { self-control motivation. } \\
\text { - Studies often try to induce ego-depletion with tasks } \\
\text { using a neutral inducer of desire (e.g., neutral stimuli), } \\
\text { which could be sub-optimal. }\end{array}$} & $\begin{array}{l}\text { Perspective 3.1: Pre-tests of self-control fatigue task } \\
\text { - Pre-test the relations between selected task and self-control correlates } \\
\text { (e.g., individual differences in self-control, daily-life conflict resolution } \\
\text { performance, performance among conflict resolution task). }\end{array}$ \\
\hline & $\begin{array}{l}\text { Perspective 3.2: Assessing the affective charge of the tasks, among individuals } \\
\text { with higher-order goal. } \\
\text { - Consider the role of desire strength, the higher-order goal type (i.e., } \\
\text { autonomous or controlled), the self-control motivation, and the self- } \\
\text { control persistence among fatiguing tasks to understand the phenomenon. } \\
\text { - Investigate the effect of affective desire inducer (e.g., affective stimuli) } \\
\text { threatening and autonomous goal on self-control fatigue research. }\end{array}$ \\
\hline
\end{tabular}




\section{Conclusion}

When a theory is falsified, scientists can revise or reject it (Dienes, 2008; Lakatos, 1978; Popper, 1935). In past years, the low replicability of ego-depletion has led many scientists to reject it. Yet, this low replicability applies mostly to studies suffering from theoretical and methodological limitations. To overcome them, researchers in the field need to reach a consensus on a definition. Based on a contemporary self-control definition (e.g., Gillebaart, 2018), we suggested one where self-control fatigue refers to the temporary reduction in selfcontrol resources, willingness and/or capacity, resulting from an initial effortful self-control act, and impairing a subsequent effortful self-control act. With this innovative approach, we aim to test it as a whole, overcoming the limitations of ego-depletion literature through the investigation of the auxiliary hypotheses that are related to the three core assumptions of the theory (i.e., shift in self-control resources, willingness, and capacity). The propositions we have made are not without limitations. First, most of the ego-depletion literature is not in line with the self-control definition we propose, and few of them used methodologies consistent with our propositions (e.g., multicomponent approaches, validated affectively-charged selfcontrol tasks). Consequently, even if some studies support the self-control fatigue theory, our suggestions require extensive empirical evidence. Second, some arguments are based on propositions from a group of ego-depletion researchers who share our perspectives, but could be in opposition with other authors. Nevertheless, our theoretical perspectives are also supported by recent empirical results. For example, a promising mental-fatigue study (Mlynski et al., 2021) showed that the decrease in behavioral restraint capacity (i.e., inhibitory control, that could serve as an operationalization of self-control capacity) can be explained by multiple interacting mechanisms, among which the motivation to restraint, which could be considered as an operationalization of self-control motivation, has proven to be particularly relevant. However, the study by Mlynski et al. (2021) does not fully relate to the self-control fatigue theory. First, the study was conducted in a mental-fatigue context, not a self-control one (e.g., no motivational conflict to resolve, extrinsic motivation, neutral cognitive tasks). Second, the authors stressed the importance of components such as behavioral restraint difficulty and behavioral restraint effort, which have not yet been explored in the ego-depletion literature. Finally, the authors investigated the role of the components' absolute score on fatigue rather than the role of the components' relative score (i.e., the role of the shift of these components' score between before and after the fatiguing task) as proposed here. Nevertheless, the findings from Mlynski et al. (2021) provides important perspectives that need to be investigated in future studies to further extend the self-control fatigue theory (see "Perspective 4.1." in Supplementary Material 2 for a discussion on some work from these authors).

To conclude, we consider that if researchers could reach a consensus on using an accurate, comprehensive, and falsifiable definition, conceptualizing self-control fatigue as a specific type of mental fatigue, and using tasks that have proven to trigger a motivational conflict requiring effortful strategies to be resolved, it could improve self-control fatigue studies' rigor, replicability, and falsifiability because of reduced flexibility in designs, definitions and outcomes (Ioannidis, 2005). It could also pave the way for further consensus proposals, and contribute to discussions about self-control fatigue. Ultimately, moving from narrow and limited investigations of ego depletion, toward comprehensive and more rigorous investigations of self-control fatigue can help to explore and understand this phenomenon. 
FROM EGO DEPLETION TO SELF-CONTROL FATIGUE

\section{Acknowledgement}

We are thankful to A.C. for his contribution to the analyses presented on the supplementary material of the manuscript, and E.D. for her final proofreading. 


\section{References}

Atherton, O. E., Lawson, K. M., \& Robins, R. W. (2020). The development of effortful control from late childhood to young adulthood. Journal of Personality and Social Psychology, 119(2), 417-456. https://doi.org/10.1037/pspp0000283

Baumeister, R. F. (2014). Self-regulation, ego depletion, and inhibition. Neuropsychologia, $65,313-319$.

Baumeister, R. F. (2018). Self-regulation and self-control: Selected works of Roy F. Baumeister. In Self-Regulation and Self-Control: Selected Works of Roy F. Baumeister (Vol. 54). Routledge. https://doi.org/10.4324/9781315175775

Baumeister, R. F. (2019). Self-control, ego depletion, and social psychology's replication crisis. In PsyArXiv. https://doi.org/10.31234/osf.io/uf3cn

Baumeister, R. F., Bratslavsky, E., Muraven, M., \& Tice, D. M. (1998). Ego depletion: Is the active self a limited resource? Journal of Personality and Social Psychology, 74(5), 1252-1265. https://doi.org/10.1037/0022-3514.74.5.1252

Baumeister, R. F., Muraven, M., \& Tice, D. M. (2000). Ego depletion: a resource model of volition, self-regulation, and controlled processing. Social Cognition, 18(2), 130-150. https://doi.org/10.1521/soco.2000.18.2.130

Baumeister, R. F., \& Vohs, K. D. (2007). Self-regulation, ego depletion, and motivation. Social and Personality Psychology Compass, 1(1), 115-128. https://doi.org/10.1111/j.1751-9004.2007.00001.x

Baumeister, R. F., \& Vohs, K. D. (2016). Misguided effort with elusive implications. Perspectives on Psychological Science, 11(4), 574-575. https://doi.org/10.1177/1745691616652878

Baumeister, R. F., \& Vohs, K. D. (2018). Strength model of self-regulation as limited resource: Assessment, controversies, update. In Self-Regulation and Self-Control: Selected Works of Roy F. Baumeister (Vol. 54, pp. 78-128). Elsevier. https://doi.org/10.4324/9781315175775

Baumeister, R. F., Vohs, K. D., \& Tice, D. M. (2007). The strength model of self-control. Current Directions in Psychological Science, 16(6), 351-355. https://doi.org/10.1111/j.1467-8721.2007.00534.x

Berkman, E. T., \& Miller-Ziegler, J. S. (2013). Imaging depletion: fMRI provides new insights into the processes underlying ego depletion. Social Cognitive and Affective Neuroscience, 8(4), 359-361. https://doi.org/10.1093/scan/nss111

Boat, R., Hunte, R., Welsh, E., Dunn, A., Treadwell, E., \& Cooper, S. B. (2020). Manipulation of the duration of the initial self-control task within the sequential-task paradigm: Effect on exercise performance. Frontiers in Neuroscience, 14, 1093. https://doi.org/10.3389/fnins.2020.571312

Boksem, M. A. S., \& Tops, M. (2008). Mental fatigue: Costs and benefits. Brain Research Reviews, 59(1), 125-139. https://doi.org/10.1016/j.brainresrev.2008.07.001

Boucher, H. C., \& Kofos, M. N. (2012). The idea of money counteracts ego depletion effects. Journal of Experimental Social Psychology, 48(4), 804-810.

Carbine, K. A., Christensen, E., LeCheminant, J. D., Bailey, B. W., Tucker, L. A., \& Larson, M. J. (2017). Testing food-related inhibitory control to high- and low-calorie food stimuli: Electrophysiological responses to high-calorie food stimuli predict calorie and carbohydrate intake. Psychophysiology, 54(7), 982-997. 
https://doi.org/10.1111/psyp.12860

Carter, E. C., Kofler, L. M., Forster, D. E., \& McCullough, M. E. (2015). A series of metaanalytic tests of the depletion effect: Self-control does not seem to rely on a limited resource. Journal of Experimental Psychology: General, 144(4), 796-815. https://doi.org/10.1037/xge0000083

Carter, E. C., \& McCullough, M. E. (2013). Is ego depletion too incredible? Evidence for the overestimation of the depletion effect. Behavioral and Brain Sciences, 36(6), 683-684. https://doi.org/10.1017/S0140525X13000952

Carter, E. C., \& McCullough, M. E. (2014). Publication bias and the limited strength model of self-control: has the evidence for ego depletion been overestimated? Frontiers in Psychology, 5(823). https://doi.org/10.3389/fpsyg.2014.00823

Cheval, B., Cabral, D. A. R., Daou, M., Bacelar, M. F. B., Parma, J. O., Forestier, C., Orsholits, D., Maltagliati, S., Sander, D., Boisgontier, M. P., \& Miller, M. W. (2021). Inhibitory control elicited by physical activity and inactivity stimuli: An electroencephalography study. Motivation Science, 7(4), 386-399. https://doi.org/10.1037/mot0000236

Cheval, B., Daou, M., Cabral, D. A. R., Bacelar, M. F. B., Parma, J. O., Forestier, C., Orsholits, D., Sander, D., Boisgontier, M. P., \& Miller, M. W. (2020). Higher inhibitory control is required to escape the innate attraction to effort minimization. Psychology of Sport and Exercise, 51, 101781. https://doi.org/10.1016/j.psychsport.2020.101781

Cheval, B., Sarrazin, P., Boisgontier, M. P., \& Radel, R. (2017). Temptations toward behaviors minimizing energetic costs (BMEC) automatically activate physical activity goals in successful exercisers. Psychology of Sport and Exercise, 30, 110-117. https://doi.org/10.1016/j.psychsport.2017.02.006

Christiansen, P., Cole, J. C., \& Field, M. (2012). Ego depletion increases Ad-Lib alcohol consumption: Investigating cognitive mediators and moderators. Experimental and Clinical Psychopharmacology, 20(2), 118-128. https://doi.org/10.1037/a0026623

Clarkson, J. J., Hirt, E. R., Chapman, D. A., \& Jia, L. (2011). The impact of illusory fatigue on executive control: Do perceptions of depletion impair working memory capacity? Social Psychological and Personality Science, 2(3), 231-238. https://doi.org/10.1177/1948550610386628

Clarkson, J. J., Hirt, E. R., Jia, L., \& Alexander, M. B. (2010). When perception is more than reality: The effects of perceived versus actual resource depletion on self-regulatory behavior. Journal of Personality and Social Psychology, 98(1), 29-46. https://doi.org/10.1037/a0017539

Clarkson, J. J., Otto, A. S., Hassey, R., \& Hirt, E. R. (2016). Perceived mental fatigue and self-control. In Self-Regulation and Ego Control (Vol. 82, Issue 3, pp. 185-202). Elsevier. https://doi.org/10.1016/B978-0-12-801850-7.00010-X

Coles, N. A., Tiokhin, L., Scheel, A. M., Isager, P. M., \& Lakens, D. (2018). The costs and benefits of replication studies. The Behavioral and Brain Sciences, 41, e124. https://doi.org/10.1017/S0140525X18000596

Converse, B. A., Juarez, L., \& Hennecke, M. (2019). Self-control and the reasons behind our goals. Journal of Personality and Social Psychology, 116(5), 860-883. https://doi.org/10.1037/pspp0000188

Cook, D. B., O’Connor, P. J., Lange, G., \& Steffener, J. (2007). Functional neuroimaging correlates of mental fatigue induced by cognition among chronic fatigue syndrome 
patients and controls. NeuroImage, 36(1), 108-122.

https://doi.org/10.1016/j.neuroimage.2007.02.033

Crandall, C. S., \& Sherman, J. W. (2016). On the scientific superiority of conceptual replications for scientific progress. Journal of Experimental Social Psychology, 66, 9399. https://doi.org/10.1016/j.jesp.2015.10.002

Dang, J. (2016). Commentary: A multilab preregistered replication of the ego-depletion effect. Frontiers in Psychology, 7, 1155. https://doi.org/10.3389/fpsyg.2016.01155

Dang, J. (2018). An updated meta-analysis of the ego depletion effect. Psychological Research, 82(4), 645-651. https://doi.org/10.1007/s00426-017-0862-x

Dang, J., Barker, P., Baumert, A., Bentvelzen, M., Berkman, E., Buchholz, N., Buczny, J., Chen, Z., De Cristofaro, V., de Vries, L., Dewitte, S., Giacomantonio, M., Gong, R., Homan, M., Imhoff, R., Ismail, I., Jia, L., Kubiak, T., Lange, F., ... Zinkernagel, A. (2020). A multilab replication of the ego depletion effect. Social Psychological and Personality Science, 12(1), 14-24. https://doi.org/10.1177/1948550619887702

Dang, J., Björklund, F., \& Bäckström, M. (2017). Self-control depletion impairs goal maintenance: A meta-analysis. Scandinavian Journal of Psychology, 58(4), 284-293. https://doi.org/10.1111/sjop.12371

Dang, J., Liu, Y., Liu, X., \& Mao, L. (2017). The ego could be depleted, providing initial exertion is depleting: A preregistered experiment of the ego depletion effect. Social Psychology, 48(4), 242-245. https://doi.org/10.1027/1864-9335/a000308

de Ridder, D. T. D., Kroese, F., \& Gillebaart, M. (2018). Whatever happened to self-control? A proposal for integrating notions from trait self-control studies into state self-control research. Motivation Science, 4(1), 39-49. https://doi.org/10.1037/mot0000062

DeWall, C. N., Baumeister, R. F., Stillman, T. F., \& Gailliot, M. T. (2007). Violence restrained: Effects of self-regulation and its depletion on aggression. Journal of Experimental Social Psychology, 43(1), 62-76. https://doi.org/10.1016/j.jesp.2005.12.005

Diamond, A. (2013). Executive functions. Annual Review of Psychology, 64(1), 135-168. https://doi.org/10.1146/annurev-psych-113011-143750

Dienes, Z. (2008). Understanding psychology as a science: An introduction to scientific and statistical inference. Macmillan International Higher Education.

Drummond, A., \& Philipp, M. C. (2017). Commentary: "Misguided effort with elusive implications" and "A multi-lab pre-registered replication of the ego depletion effect." Frontiers in Psychology, 8, 214-221. https://doi.org/10.3389/fpsyg.2017.00273

Duckworth, A. L., \& Kern, M. L. (2011). A meta-analysis of the convergent validity of selfcontrol measures. Journal of Research in Personality, 45(3), 259-268. https://doi.org/10.1016/j.jrp.2011.02.004

Duckworth, A. L., Milkman, K. L., \& Laibson, D. (2018). Beyond willpower: Strategies for reducing failures of self-control. Psychological Science in the Public Interest: A Journal of the American Psychological Society, 19(3), 102-129. https://doi.org/10.1177/1529100618821893

Englert, C., Zwemmer, K., Bertrams, A., \& Oudejans, R. R. D. (2015). Ego depletion and attention regulation under pressure: Is a temporary loss of self-control strength indeed related to impaired attention regulation? Journal of Sport and Exercise Psychology, 37(2), 127-137. https://doi.org/10.1123/jsep.2014-0219 
Ent, M. R., Baumeister, R. F., \& Tice, D. M. (2015). Trait self-control and the avoidance of temptation. Personality and Individual Differences, 74, 12-15. https://doi.org/10.1016/j.paid.2014.09.031

Etherton, J. L., Osborne, R., Stephenson, K., Grace, M., Jones, C., \& De Nadai, A. S. (2018). Bayesian analysis of multimethod ego-depletion studies favours the null hypothesis. British Journal of Social Psychology, 57(2), 367-385. https://doi.org/10.1111/bjso.12236

Fillmore, M. T., \& Vogel-Sprott, M. (2000). Response inhibition under alcohol: effects of cognitive and motivational conflict. Journal of Studies on Alcohol, 61(2), 239-246. https://doi.org/10.15288/jsa.2000.61.239

Finkel, E. J., Campbell, W. K., Brunell, A. B., Dalton, A. N., Scarbeck, S. J., \& Chartrand, T. L. (2006). High-maintenance interaction: Inefficient social coordination impairs selfregulation. Journal of Personality and Social Psychology, 91(3), 456-475. https://doi.org/10.1037/0022-3514.91.3.456

Fishbach, A., Friedman, R. S., \& Kruglanski, A. W. (2003). Leading us not unto temptation: Momentary allurements elicit overriding goal activation. Journal of Personality and Social Psychology, 84(2), 296-309. https://doi.org/10.1037/0022-3514.84.2.296

Francis, Z., Milyavskaya, M., Lin, H., \& Inzlicht, M. (2018). Development of a withinsubject, repeated-measures ego-depletion paradigm: Inconsistent results and future recommendations. Social Psychology, 49(5), 271-286. https://doi.org/10.1027/18649335/a000348

Friese, M., Engeler, M., \& Florack, A. (2015). Self-perceived successful weight regulators are less affected by self-regulatory depletion in the domain of eating behavior. Eating Behaviors, 16, 5-8. https://doi.org/10.1016/j.eatbeh.2014.10.011

Friese, M., Loschelder, D. D., Gieseler, K., Frankenbach, J., \& Inzlicht, M. (2019). Is ego depletion real? An analysis of arguments. Personality and Social Psychology Review, 23(2), 107-131. https://doi.org/10.1177/1088868318762183

Fujita, K. (2011). On conceptualizing self-control as more than the effortful inhibition of impulses. Personality and Social Psychology Review, 15(4), 352-366. https://doi.org/10.1177/1088868311411165

Fujita, K., \& Han, H. A. (2009). Moving beyond deliberative control of impulses: The effect of construal levels on evaluative associations in self-control conflicts. Psychological Science, 20(7), 799-804. https://doi.org/10.1111/j.1467-9280.2009.02372.x

Gailliot, M. T., Baumeister, R. F., Dewall, C. N., Maner, J. K., Plant, E. A., Tice, D. M., Brewer, L. E., \& Schmeichel, B. J. (2007). Self-control relies on glucose as a limited energy source: Willpower is more than a metaphor. Journal of Personality and Social Psychology, 92(2), 325-336. https://doi.org/10.1037/0022-3514.92.2.325

Gailliot, M. T., Schmeichel, B. J., \& Maner, J. K. (2007). Differentiating the effects of selfcontrol and self-esteem on reactions to mortality salience. Journal of Experimental Social Psychology, 43(6), 894-901. https://doi.org/10.1016/j.jesp.2006.10.011

Garrison, K. E., Finley, A. J., \& Schmeichel, B. J. (2019). Ego depletion reduces attention control: Evidence from two high-powered preregistered experiments. Personality and Social Psychology Bulletin, 45(5), 728-739. https://doi.org/10.1177/0146167218796473

Georgii, C., Schulte-Mecklenbeck, M., Richard, A., Van Dyck, Z., \& Blechert, J. (2020). The dynamics of self-control: within-participant modeling of binary food choices and underlying decision processes as a function of restrained eating. Psychological Research, 84(7), 1777-1788. https://doi.org/10.1007/s00426-019-01185-3 
Gergelyfi, M., Jacob, B., Olivier, E., \& Zénon, A. (2015). Dissociation between mental fatigue and motivational state during prolonged mental activity. Frontiers in Behavioral Neuroscience, 9, 176. https://doi.org/10.3389/fnbeh.2015.00176

Giboin, L. S., \& Wolff, W. (2019). The effect of ego depletion or mental fatigue on subsequent physical endurance performance: A meta-analysis. Performance Enhancement and Health, 7(1-2), 100150. https://doi.org/10.1016/j.peh.2019.100150

Gillebaart, M. (2018). The 'operational' definition of self-control. Frontiers in Psychology, 9, 1231. https://doi.org/10.3389/fpsyg.2018.01231

Hagger, M. S., \& Chatzisarantis, N. L. D. (2016). Commentary: Misguided effort with elusive implications, and sifting signal from noise with replication science. Frontiers in Psychology, 7(APR), 1-3. https://doi.org/10.3389/fpsyg.2016.00621

Hagger, M. S., Chatzisarantis, N. L. D., Alberts, H., Anggono, C. O., Batailler, C., Birt, A. R., Brand, R., Brandt, M. J., Brewer, G. A., Bruyneel, S., Calvillo, D. P., Campbell, W. K., Cannon, P. R., Carlucci, M., Carruth, N. P., Cheung, T. T. L., Crowell, A., De Ridder, D. T. D., Dewitte, S., ... Zwienenberg, M. (2016). A multilab preregistered replication of the ego-depletion effect. Perspectives on Psychological Science, 11(4), 546-573. https://doi.org/10.1177/1745691616652873

Hagger, M. S., Wood, C., Stiff, C., \& Chatzisarantis, N. L. D. (2010). Ego depletion and the strength model of self-control: A meta-analysis. Psychological Bulletin, 136(4), 495525. https://doi.org/10.1037/a0019486

Harms, C., \& Lakens, D. (2018). Making "null effects" informative: statistical techniques and inferential frameworks. Journal of Clinical and Translational Research, 3, 382-393. https://doi.org/10.18053/jctres.03.2017S2.007

Hedgcock, W. M., Vohs, K. D., \& Rao, A. R. (2012). Reducing self-control depletion effects through enhanced sensitivity to implementation: Evidence from fMRI and behavioral studies. Journal of Consumer Psychology, 22(4), 486-495. https://doi.org/10.1016/j.jcps.2012.05.008

Hirt, E. R., Clarkson, J. J., \& Jia, L. (2016). Self-regulation and ego control. In SelfRegulation and Ego Control. Elsevier. https://doi.org/10.1016/C2014-0-01291-9

Hofmann, W., Adriaanse, M., Vohs, K. D., \& Baumeister, R. F. (2014). Dieting and the selfcontrol of eating in everyday environments: An experience sampling study. British Journal of Health Psychology, 19(3), 523-539. https://doi.org/10.1111/bjhp.12053

Hofmann, W., Baumeister, R. F., Förster, G., \& Vohs, K. D. (2012). Everyday temptations: An experience sampling study of desire, conflict, and self-control. Journal of Personality and Social Psychology, 102(6), 1318-1335. https://doi.org/10.1037/a0026545

Hofmann, W., Schmeichel, B. J., \& Baddeley, A. D. (2012). Executive functions and selfregulation. Trends in Cognitive Sciences, 16(3), 174-180. https://doi.org/10.1016/j.tics.2012.01.006

Inzlicht, M., \& Gutsell, J. N. (2007). Running on empty: Neural signals for self-control failure. Psychological Science, 18(11), 933-937. https://doi.org/10.1111/j.14679280.2007.02004.x

Inzlicht, M., \& Schmeichel, B. J. (2012). What is ego depletion? Toward a mechanistic revision of the resource model of self-control. Perspectives on Psychological Science, 7(5), 450-463. https://doi.org/10.1177/1745691612454134

Ioannidis, J. P. A. (2005). Why most published research findings are false. PLoS Medicine, 2(8), e124. https://doi.org/10.1371/journal.pmed.0020124 
Kemps, E., Tiggemann, M., Martin, R., \& Elliott, M. (2013). Implicit approach-avoidance associations for craved food cues. Journal of Experimental Psychology: Applied, 19(1), 30 .

Kotabe, H. P., \& Hofmann, W. (2015). On integrating the components of self-control. Perspectives on Psychological Science, 10(5), 618-638. https://doi.org/10.1177/1745691615593382

Krieglmeyer, R., \& Deutsch, R. (2010). Comparing measures of approach-avoidance behaviour: The manikin task vs. two versions of the joystick task. Cognition and Emotion, 24(5), 810-828. https://doi.org/10.1080/02699930903047298

Kurzban, R. (2010). Does the brain consume additional glucose during self-control tasks? Evolutionary Psychology, 8(2), 244-259. https://doi.org/10.1177/147470491000800208

Kurzban, R., Duckworth, A., Kable, J. W., \& Myers, J. (2013). An opportunity cost model of subjective effort and task performance. Behavioral and Brain Sciences, 36(6), 661-679. https://doi.org/10.1017/S0140525X12003196

Laborde, S., Mosley, E., \& Mertgen, A. (2018). Vagal tank theory: The three Rs of cardiac vagal control functioning - resting, reactivity, and recovery. Frontiers in Neuroscience, 12, 458. https://doi.org/10.3389/fnins.2018.00458

Lakatos, I. (1978). The methodology of scientific research programmes. Philosophical Papers, 1, 250.

Lin, H., Saunders, B., Friese, M., Evans, N. J., \& Inzlicht, M. (2020). Strong effort manipulations reduce response caution: A preregistered reinvention of the ego-depletion paradigm. Psychological Science, 31(5), 531-547. https://doi.org/10.1177/0956797620904990

Loevinger, J. (2014). Measuring ego development. Psychology Press.

Lurquin, J. H., \& Miyake, A. (2017). Challenges to ego-depletion research go beyond the replication crisis: A need for tackling the conceptual crisis. Frontiers in Psychology, 8, 568. https://doi.org/10.3389/fpsyg.2017.00568

Marcora, S. M., Staiano, W., \& Manning, V. (2009). Mental fatigue impairs physical performance in humans. Journal of Applied Physiology, 106(3), 857-864. https://doi.org/10.1152/japplphysiol.91324.2008

Martijn, C., Alberts, H. J. E. M., Merckelbach, H., Havermans, R., Huijts, A., \& De Vries, N. K. (2007). Overcoming ego depletion: The influence of exemplar priming on self-control performance. European Journal of Social Psychology, 37(2), 231-238. https://doi.org/10.1002/ejsp.350

Mas, M., Brindisi, M. C., Chabanet, C., \& Chambaron, S. (2020). Implicit food odour priming effects on reactivity and inhibitory control towards foods. PLoS ONE, 15(6), 1-21. https://doi.org/10.1371/journal.pone.0228830

Mas, M., Brindisi, M. C., Chabanet, C., Nicklaus, S., \& Chambaron, S. (2019). Weight status and attentional biases toward foods: Impact of implicit olfactory priming. Frontiers in Psychology, 10(JULY). https://doi.org/10.3389/fpsyg.2019.01789

Mead, N. L., Baumeister, R. F., Gino, F., Schweitzer, M. E., \& Ariely, D. (2009). Too tired to tell the truth: Self-control resource depletion and dishonesty. Journal of Experimental Social Psychology, 45(3), 594-597.

Milyavskaya, M., Berkman, E. T., \& de Ridder, D. T. D. (2019). The many faces of selfcontrol: Tacit assumptions and recommendations to deal with them. Motivation Science, 


\section{5(1), 79-85. https://doi.org/10.1037/mot0000108}

Milyavskaya, M., Inzlicht, M., Hope, N., \& Koestner, R. (2015). Saying "no" to temptation: Want-to motivation improves self-regulation by reducing temptation rather than by increasing self-control. Journal of Personality and Social Psychology, 109(4), 677-693. https://doi.org/10.1037/pspp0000045

Mlynski, C., Reza, A., Whitted, M., Cox, C., Garsea, A., \& Wright, R. A. (2021). Fatigue influence on inhibitory control: Cardiovascular and performance findings elucidate the role of restraint intensity. Psychophysiology, 58(9), 1-18. https://doi.org/10.1111/psyp.13881

Mobbs, O., Van der Linden, M., d'Acremont, M., \& Perroud, A. (2008). Cognitive deficits and biases for food and body in bulimia: investigation using an affective shifting task. Eating Behaviors, 9(4), 455-461.

Molden, D. C., Hui, C. M., Scholer, A. A., Meier, B. P., Noreen, E. E., D’Agostino, P. R., \& Martin, V. (2012). Motivational versus metabolic effects of carbohydrates on selfcontrol. Psychological Science, 23(10), 1137-1144. https://doi.org/10.1177/0956797612439069

Muraven, M., \& Baumeister, R. F. (2000). Self-regulation and depletion of limited resources: Does self-control resemble a muscle? Psychological Bulletin, 126(2), 247-259. https://doi.org/10.1037/0033-2909.126.2.247

Muraven, M., Gagné, M., \& Rosman, H. (2008). Helpful self-control: Autonomy support, vitality, and depletion. Journal of Experimental Social Psychology, 44(3), 573-585. https://doi.org/10.1016/j.jesp.2007.10.008

Muraven, M., \& Slessareva, E. (2003). Mechanisms of self-control failure: Motivation and limited resources. Personality and Social Psychology Bulletin, 29(7), 894-906. https://doi.org/10.1177/0146167203029007008

O'Keeffe, K., Hodder, S., \& Lloyd, A. (2020). A comparison of methods used for inducing mental fatigue in performance research: individualised, dual-task and short duration cognitive tests are most effective. Ergonomics, 63(1), 1-12. https://doi.org/10.1080/00140139.2019.1687940

Open Science Collaboration. (2015). Estimating the reproducibility of psychological science. Science, 349(6251), aac4716-aac4716. https://doi.org/10.1126/science.aac4716

Ozaki, Y., Goto, T., Kobayashi, M., \& Hofmann, W. (2017). Counteractive control over temptations: Promoting resistance through enhanced perception of conflict and goal value. Self and Identity, 16(4), 439-459. https://doi.org/10.1080/15298868.2016.1269668

Pawliczek, C. M., Derntl, B., Kellermann, T., Kohn, N., Gur, R. C., \& Habel, U. (2013). Inhibitory control and trait aggression: neural and behavioral insights using the emotional stop signal task. Neuroimage, 79, 264-274.

Pfeffer, I., \& Strobach, T. (2017). Executive functions, trait self-control, and the intentionbehavior gap in physical activity behavior. Journal of Sport and Exercise Psychology, 39(4), 277-292. https://doi.org/10.1123/jsep.2017-0112

Popper, K. (1935). The Logic of Scientific Discovery.

Radel, R., Gruet, M., \& Barzykowski, K. (2019). Testing the ego-depletion effect in optimized conditions. PLoS ONE, 14(3), 1-15. https://doi.org/10.1371/journal.pone.0213026 
Rouse, P. C., Ntoumanis, N., \& Duda, J. L. (2013). Effects of motivation and depletion on the ability to resist the temptation to avoid physical activity. International Journal of Sport and Exercise Psychology, 11(1), 39-56. https://doi.org/10.1080/1612197X.2012.717779

Ryan, R. M., \& Deci, E. L. (2008). From ego depletion to vitality: Theory and findings concerning the facilitation of energy available to the self. Social and Personality Psychology Compass, 2(2), 702-717. https://doi.org/10.1111/j.1751-9004.2008.00098.x

Schimmack, U. (2012). The ironic effect of significant results on the credibility of multiplestudy articles. Psychological Methods, 17(4), 551-566. https://doi.org/10.1037/a0029487

Schimmack, U. (2016). Ego Depletion | Replicability-Index. https://replicationindex.com/category/ego-depletion/

Schmeichel, B. J., Harmon-Jones, C., \& Harmon-Jones, E. (2010). Exercising self-control increases approach motivation. Journal of Personality and Social Psychology, 99(1), 162.

Segerstrom, S. C., \& Nes, L. S. (2007). Heart rate variability reflects self-regulatory strength, effort, and fatigue. Psychological Science, 18(3), 275-281. https://doi.org/10.1111/j.1467-9280.2007.01888.x

Sellahewa, D. A., \& Mullan, B. (2015). Health behaviours and their facilitation under depletion conditions: The case of snacking. Appetite, 90, 194-199.

Smith, M. R., Chai, R., Nguyen, H. T., Marcora, S. M., \& Coutts, A. J. (2019). Comparing the effects of three cognitive tasks on indicators of mental fatigue. Journal of Psychology: Interdisciplinary and Applied, 153(8), 759-783. https://doi.org/10.1080/00223980.2019.1611530

Stillman, P. E., Shen, X., \& Ferguson, M. J. (2018). How mouse-tracking can advance social cognitive theory. Trends in Cognitive Sciences, 22(6), 531-543. https://doi.org/10.1016/j.tics.2018.03.012

Tangney, J. P., Baumeister, R. F., \& Boone, A. L. (2004). High self-control predicts good adjustment, less pathology, better grades, and interpersonal success. Journal of Personality, 72(2), 271-324. https://doi.org/10.1111/j.0022-3506.2004.00263.x

Unger, A., \& Stahlberg, D. (2011). Ego-depletion and risk behavior: Too exhausted to take a risk. Social Psychology, 42(1), 28-38. https://doi.org/10.1027/1864-9335/a000040

Uygun Tunç, D., \& Tunç, M. N. (2020). A falsificationist treatment of auxiliary hypotheses in social and behavioral sciences: Systematic replications framework. PsyArXiv. https://doi.org/10.31234/osf.io/pdm7y

Vadillo, M. A. (2019). Ego depletion may disappear by 2020. Social Psychology, 50(5-6), 282-291. https://doi.org/10.1027/1864-9335/a000375

Vadillo, M. A., Gold, N., \& Osman, M. (2016). The bitter truth about sugar and willpower: The limited evidential value of the glucose model of ego depletion. Psychological Science, 27(9), 1207-1214. https://doi.org/10.1177/0956797616654911

Vadillo, M. A., Gold, N., \& Osman, M. (2018). Searching for the bottom of the ego well: Failure to uncover ego depletion in Many Labs 3. Royal Society Open Science, 5(8), 180390. https://doi.org/10.1098/rsos.180390

Van Cutsem, J., Marcora, S., De Pauw, K., Bailey, S., Meeusen, R., \& Roelands, B. (2017). The effects of mental fatigue on physical performance: A systematic review. Sports Medicine, 47(8), 1569-1588. https://doi.org/10.1007/s40279-016-0672-0

Van der Linden, D., Frese, M., \& Meijman, T. F. (2003). Mental fatigue and the control of 
cognitive processes: effects on perseveration and planning. Acta Psychologica, 113(1), $45-65$.

Vohs, K. D., Baumeister, R. F., \& Ciarocco, N. J. (2005). Self-regulation and selfpresentation: Regulatory resource depletion impairs impression management and effortful self-presentation depletes regulatory resources. Journal of Personality and Social Psychology, 88(4), 632-657. https://doi.org/10.1037/0022-3514.88.4.632

Vohs, K. D., Baumeister, R. F., \& Schmeichel, B. J. (2013). Erratum to "Motivation, personal beliefs, and limited resources all contribute to self-control". [J. Exp. Soc. Psychol. 48 (2012) 943-947]. Journal of Experimental Social Psychology, 49(1), 184-188. https://doi.org/10.1016/j.jesp.2012.08.007

Vohs, K. D., Schmeichel, B. J., Gronau, Q. F., Finley, A., Wagenmakers, E. J., \& Albarracín, D. (2021). A multi-site preregistered paradigmatic test of the ego depletion effect. Psychological Science.

Wang, Y., \& Yang, L. (2014). Suppression (but not reappraisal) impairs subsequent error detection: An ERP study of emotion regulation's resource-depleting effect. PLoS ONE, 9(4), e96339. https://doi.org/10.1371/journal.pone.0096339

Wimmer, M. C., Dome, L., Hancock, P. J. B., \& Wennekers, T. (2019). Is the letter cancellation task a suitable index of ego depletion?: Empirical and conceptual issues. Social Psychology, 50(5-6), 345-354. https://doi.org/10.1027/1864-9335/a000393

Wolff, W., Baumgarten, F., \& Brand, R. (2013). Reduced self-control leads to disregard of an unfamiliar behavioral option: An experimental approach to the study of neuroenhancement. Substance Abuse: Treatment, Prevention, and Policy, 8(1), 1-6. https://doi.org/10.1186/1747-597X-8-41

Wright, R. A., \& Mlynski, C. (2019). Fatigue determination of inhibitory strength and control: A babe in a bath. Motivation Science, 5(1), 66-78. https://doi.org/10.1037/mot0000114

Wright, R. A., Mlynski, C., \& Carbajal, I. (2019). Outsiders' thoughts on generating selfregulatory-depletion (fatigue) effects in limited-resource experiments. Perspectives on Psychological Science, 14(3), 469-480. https://doi.org/10.1177/1745691618815654

Wright, R. A., Patrick, B. M., Thomas, C., \& Barreto, P. (2013). When fatigue promotes striving: Confirmation that success importance moderates resource depletion influence on effort-related cardiovascular response. Biological Psychology, 93(2), 316-324. https://doi.org/10.1016/j.biopsycho.2013.02.016 


\section{Supplementary Material 1}

\section{Limitation 4: The need for protocols that explore the complexity of self-control fatigue}

To date, the ego-depletion literature has been dominated by studies using between-group designs based on the sequential-task paradigm. These designs are associated with several limitations (Francis et al., 2018). First, between-group designs cannot provide insights into the intra-individual dynamics of ego depletion or self-control fatigue and cannot answer several important questions such as the following: Is self-control performance linearly and negatively related to the time spent exerting an effortful self-control strategy? Is there, similar to the relation between effort and fatigue (e.g., Mlynski et al., 2021; Wright \& Mlynski, 2019), a nonlinear relationship (e.g., inverted U-shape) where self-control initially increases with fatigue until it reaches a threshold where self-control starts declining? Does self-control first decrease, then increases before a final decrease, similar to what could be observed in mental fatigue (e.g., Deschamps et al., 2013)? Second, and as mentioned above, the focus on the sequential-task paradigm prevents a comprehensive exploration of the three core assumptions of self-control fatigue theory. Focusing on a single method, as ego-depletion literature did, also restricts the diversity of the markers used to test the auxiliary hypotheses, thereby limiting the possibility to investigate all the effects that could further explain the phenomenon. For example, studies showed that mentally fatigued individuals can maintain similar cognitive performance as nonfatigued individuals by investing extra cognitive effort to compensate for the effects of mental fatigue (for recent reviews, see Wright et al., 2019; Wright \& Mlynski, 2019, and for recent promising results, see Mlynski et al., 2021). Accordingly, mental fatigue could be characterized by a change in invested effort rather than a change in cognitive performance. If self-control fatigue is a particular type of mental fatigue, it follows that self-control performance can be maintained by investing extra cognitive effort to compensate for the effects of self-control fatigue, thereby leading to erroneous conclusions about the absence of self-control fatigue. Therefore, to avoid such errors, markers of self-control fatigue should be diversified in future research.

\section{Perspective 4.1: Using within-person designs and focusing on self-control across the depleting task}

To date, only one study has investigated the intra-individual dynamics of ego depletion (Arber et al., 2017). This study showed a linear decline of performance during the depleting task. However, this innovative study had several limitations, such as a potentially inappropriate depletion task (i.e., letter cancellation tasks) and no measures of self-control resources or willingness. Therefore, additional studies are required to improve our understanding of the within-person dynamics of ego depletion. In 2015, an article (Job et al., 2015)was the first to discuss within-person variation in time spent sitting on chairs following a depletion task versus a control task. Precisely, the authors aimed to identify a within-person motivational shift toward rest after self-control exertion in people holding a limited-resource theory about willpower. However, in this study the authors were not interested in within-person variations of self-control act consecutively to a depletion condition or control condition, but focused on a recovery goal, which remains interesting but does not inform about within-person self-control fluctuations. A recent study initiated a research line focusing on self-control fluctuations with the development 
of a within-subject design to test ego depletion. The study found a significant meta-analytic effect $(\mathrm{d}=.045)$ despite manipulations that did not consistently affect self-control. Authors showed that self-control performance changed across the course of the experiment (e.g., participants performed worse on the 20th self-control task compared to the 1st). However, this study did not inform regarding whether self-control performance changed across (i.e., withinperson and within-task analyses) each depleting task (e.g., did participants perform worse on the 32 nd trials compared to the 1 st?).

Despite these limitations, these three studies are promising for future self-control fatigue research based on within-person designs. Precisely, the studies should investigate the evolution of the three self-control fatigue components across the fatiguing task (e.g., repeated measures of self-control resources, willingness and capacity across the depleting task), but also across several consecutive fatiguing tasks (e.g., repeated measures of self-control resources, willingness and capacity across repeated and consecutive depleting tasks), as people may apply several consecutive self-control acts in daily life (Hofmann, Baumeister, et al., 2012; Hofmann, Vohs, et al., 2012; e.g., Hofmann et al., 2014).

\section{Perspective 4.2: Focusing on untested auxiliary hypotheses}

Moreover, we recommend focusing on the untested auxiliary hypotheses of ego depletion. Specifically, future studies should investigate the role of resources, such as perceived energy (Forestier et al., 2018; Rouse et al., 2013), perceived fatigue (Francis et al., 2018; Hirt et al., 2016), or cardiac makers (Laborde et al., 2019; Wright et al., 2019); the role of willingness, such as motivation, attention (Inzlicht \& Schmeichel, 2012), vigilance (Lin et al., 2020), or decisions related to effort cost (Kool \& Botvinick, 2014); and the role of self-control capacity, such as inhibition and attention (for a review, see Wagner \& Heatherton, 2016). We also recommend focusing on the boundary conditions of ego-depletion emergence, as few studies have examined potential moderators of ego depletion, such as the trait of self-control (Imhoff et al., 2014), perceived success attainability (Mlynski et al., 2021; Wright \& Mlynski, 2019), effort (Dang, 2016; Drummond \& Philipp, 2017; Mlynski et al., 2021; Prem et al., 2016; Wright et al., 2019; Wright \& Mlynski, 2019), and perceived fatigue (Vohs et al., 2021), despite the importance of such information to understanding ego depletion. As an example, the importance of self-control effort has recently been highlighted, but its role in self-control fatigue remains largely unknown. Our reanalyzes of Lin et al. (2020) and Vohs et al.'s (2021) datasets highlighted inconsistent results. Indeed, based on Vohs et al.'s (2021) data, self-control effort was significantly and moderately associated with self-control resources (i.e., perceived fatigue) $(\mathrm{r}=.28, \mathrm{p}<.001)$, and not associated with self-control willingness (i.e., perceived motivation) $(\mathrm{r}=.03, \mathrm{p}=.08)$, suggesting that self-control resources and willingness are distinct from selfcontrol effort. However, based on Lin et al.'s (2020) data, self-control effort was significantly and highly associated with self-control resources (i.e., perceived fatigue) $(r=.72, p<.001)$, and significantly but weakly associated with self-control capacity (i.e., inhibition on a Stroop task) $(\mathrm{r}=.02, \mathrm{p}=.05)$, suggesting that self-control effort and capacity are distinct, but that selfcontrol effort and resources are similar constructs (Supplementary Materials). Future research should consider the role of self-control effort in the emergence of self-control fatigue, and investigate whether it is a fourth core concept, or whether it could be associated (e.g., new auxiliary hypotheses) with a core concept already proposed (e.g., self-control resources). 
Other authors have suggested that ego-depletion sensitivity is subject to interindividual differences and that the optimal duration of the depleting task could be dependent on this sensitivity (Wolff et al., 2019). This suggestion is in line with recent findings in mental fatigue showing that individualized tasks are more fatiguing than non-individualized tasks (O'Keeffe et al., 2020). Accordingly, future self-control fatigue studies could investigate whether individual factors such as cognitive abilities and the sensitivity to task duration can be used to optimize the efficiency of fatiguing tasks (for examples of individualization processes, see O'Keeffe et al., 2020).

\section{Perspective 4.3: Investigating a broader operationalization of self-control fatigue}

In addition, we recommend investigating a broader operationalization of self-control fatigue markers. Some authors have suggested that the intraindividual variability of change in performance on a demanding task is a more sensitive indicator of mental fatigue than the traditional increase in mean reaction time (Wang et al., 2014). Based on these results, future self-control fatigue studies could hypothesize that the intraindividual variability change in selfcontrol performance could be a more reliable marker of self-control fatigue than the commonly used measures of central tendency. 


\section{References}

Arber, M. M., Ireland, M. J., Feger, R., Marrington, J., Tehan, J., \& Tehan, G. (2017). Ego Depletion in Real-Time: An Examination of the Sequential-Task Paradigm. Frontiers in Psychology, 8, 1672. https://doi.org/10.3389/fpsyg.2017.01672

Dang, J. (2016). Commentary: A Multilab Preregistered Replication of the Ego-Depletion Effect. Frontiers in Psychology, 7, 1155. https://doi.org/10.3389/fpsyg.2016.01155

Deschamps, T., Magnard, J., \& Cornu, C. (2013). Postural control as a function of time-ofday: Influence of a prior strenuous running exercise or demanding sustained-attention task. Journal of NeuroEngineering and Rehabilitation, 10(1), 1. https://doi.org/10.1186/1743-0003-10-26

Drummond, A., \& Philipp, M. C. (2017). Commentary: "Misguided Effort with Elusive Implications" and "A Multi-Lab Pre-Registered Replication of the Ego Depletion Effect.” Frontiers in Psychology, 8, 214-221. https://doi.org/10.3389/fpsyg.2017.00273

Forestier, C., Sarrazin, P., Allenet, B., Gauchet, A., Heuzé, J.-P., \& Chalabaev, A. (2018). "Are you in full possession of your capacity?". A mechanistic self-control approach at trait and state levels to predict different health behaviors. Personality and Individual Differences, 134, 214-221. https://doi.org/10.1016/j.paid.2018.05.044

Francis, Z., Milyavskaya, M., Lin, H., \& Inzlicht, M. (2018). Development of a WithinSubject, Repeated-Measures Ego-Depletion Paradigm: Inconsistent Results and Future Recommendations. Social Psychology, 49(5), 271-286. https://doi.org/10.1027/18649335/a000348

Hirt, E. R., Clarkson, J. J., \& Jia, L. (2016). Self-Regulation and Ego Control. In SelfRegulation and Ego Control. Elsevier. https://doi.org/10.1016/C2014-0-01291-9

Hofmann, W., Adriaanse, M., Vohs, K. D., \& Baumeister, R. F. (2014). Dieting and the selfcontrol of eating in everyday environments: An experience sampling study. British Journal of Health Psychology, 19(3), 523-539. https://doi.org/10.1111/bjhp.12053

Hofmann, W., Baumeister, R. F., Förster, G., \& Vohs, K. D. (2012). Everyday temptations: An experience sampling study of desire, conflict, and self-control. Journal of Personality and Social Psychology, 102(6), 1318-1335. https://doi.org/10.1037/a0026545

Hofmann, W., Vohs, K. D., \& Baumeister, R. F. (2012). What People Desire, Feel Conflicted About, and Try to Resist in Everyday Life. Psychological Science, 23(6), 582-588. https://doi.org/10.1177/0956797612437426

Imhoff, R., Schmidt, A. F., \& Gerstenberg, F. (2014). Exploring the interplay of trait selfcontrol and ego depletion: Empirical evidence for ironic effects. European Journal of Personality, 28(5), 413-424. https://doi.org/10.1002/per.1899

Inzlicht, M., \& Schmeichel, B. J. (2012). What Is Ego Depletion? Toward a Mechanistic Revision of the Resource Model of Self-Control. Perspectives on Psychological Science, 7(5), 450-463. https://doi.org/10.1177/1745691612454134

Job, V., Bernecker, K., Miketta, S., \& Friese, M. (2015). Implicit theories about willpower 
predict the activation of a rest goal following self-control exertion. Journal of Personality and Social Psychology, 109(4), 694-706.

https://doi.org/10.1037/pspp0000042

Kool, W., \& Botvinick, M. (2014). A labor/leisure tradeoff in cognitive control. Journal of Experimental Psychology: General, 143(1), 131-141. https://doi.org/10.1037/a0031048

Laborde, S., Lentes, T., Hosang, T. J., Borges, U., Mosley, E., \& Dosseville, F. (2019). Influence of Slow-Paced Breathing on Inhibition After Physical Exertion. Frontiers in Psychology, 10, 1923. https://doi.org/10.3389/fpsyg.2019.01923

Lin, H., Saunders, B., Friese, M., Evans, N. J., \& Inzlicht, M. (2020). Strong Effort Manipulations Reduce Response Caution: A Preregistered Reinvention of the EgoDepletion Paradigm. Psychological Science, 31(5), 531-547. https://doi.org/10.1177/0956797620904990

Mlynski, C., Reza, A., Whitted, M., Cox, C., Garsea, A., \& Wright, R. A. (2021). Fatigue influence on inhibitory control: Cardiovascular and performance findings elucidate the role of restraint intensity. Psychophysiology, 58(9), 1-18. https://doi.org/10.1111/psyp.13881

O'Keeffe, K., Hodder, S., \& Lloyd, A. (2020). A comparison of methods used for inducing mental fatigue in performance research: individualised, dual-task and short duration cognitive tests are most effective. Ergonomics, 63(1), 1-12. https://doi.org/10.1080/00140139.2019.1687940

Prem, R., Kubicek, B., Diestel, S., \& Korunka, C. (2016). Regulatory job stressors and their within-person relationships with ego depletion: The roles of state anxiety, self-control effort, and job autonomy. Journal of Vocational Behavior, 92, 22-32. https://doi.org/10.1016/j.jvb.2015.11.004

Rouse, P. C., Ntoumanis, N., \& Duda, J. L. (2013). Effects of motivation and depletion on the ability to resist the temptation to avoid physical activity. International Journal of Sport and Exercise Psychology, 11(1), 39-56. https://doi.org/10.1080/1612197X.2012.717779

Vohs, K. D., Schmeichel, B. J., Gronau, Q. F., Finley, A., Wagenmakers, E. J., \& Albarracín, D. (2021). A Multi-Site Preregistered Paradigmatic Test of the Ego Depletion Effect. Psychological Science.

Wagner, D. D., \& Heatherton, T. F. (2016). What Can Cognitive Neuroscience Tell Us About the Mechanism of Ego Depletion. In Self-Regulation and Ego Control (pp. 281-300). Elsevier. https://doi.org/10.1016/B978-0-12-801850-7.00014-7

Wang, C., Ding, M., \& Kluger, B. M. (2014). Change in intraindividual variability over time as a key metric for defining performance-based cognitive fatigability. Brain and Cognition, 85(1), 251-258. https://doi.org/10.1016/j.bandc.2014.01.004

Wolff, W., Sieber, V., Bieleke, M., \& Englert, C. (2019). Task duration and task order do not matter: no effect on self-control performance. Psychological Research, January, 1-11. https://doi.org/10.1007/s00426-019-01230-1 
Wright, R. A., \& Mlynski, C. (2019). Fatigue determination of inhibitory strength and control: A babe in a bath. Motivation Science, 5(1), 66-78. https://doi.org/10.1037/mot0000114

Wright, R. A., Mlynski, C., \& Carbajal, I. (2019). Outsiders' Thoughts on Generating SelfRegulatory-Depletion (Fatigue) Effects in Limited-Resource Experiments. Perspectives on Psychological Science, 14(3), 469-480. https://doi.org/10.1177/1745691618815654 


\section{Supplementary material 2}

«From ego depletion to self-control fatigue: A review of criticisms along with new perspectives for the investigation of a multicomponent phenomenon".

Data and code are available at:

https://osf.io/4y38k/?view_only=6ceaa44fbc454b3798452f57e0e0acf6 
Table 1. Correlations with confidence intervals between self-control resources (i.e., perceived fatigue), self-control willingness (i.e., perceived motivation), and self-control effort based on data from Vohs et al. (2021)

\begin{tabular}{lrc}
\hline Variable & \multicolumn{1}{c}{1} & \multicolumn{1}{c}{2} \\
\hline 1. Perceived fatigue & & \\
2. Perceived motivation &. $\mathbf{1 3}^{* * *}$ & \\
& {$[.09, .16]$} & \\
3. Effort & $\mathbf{. 2 8 * *}$ & .03 \\
& {$[.25, .31]$} & {$[-.00, .07]$} \\
\hline
\end{tabular}

Note. Values in square brackets indicate the $95 \%$ confidence interval for each correlation. The confidence interval is a plausible range of population correlations that could have caused the sample correlation (Cumming, 2014). ** indicates $p<.01$. 
Figure 1. Correlations between self-control resources (i.e., perceived fatigue), self-control willingness (i.e., perceived motivation), and self-control effort based on data from Vohs et al. (2021)
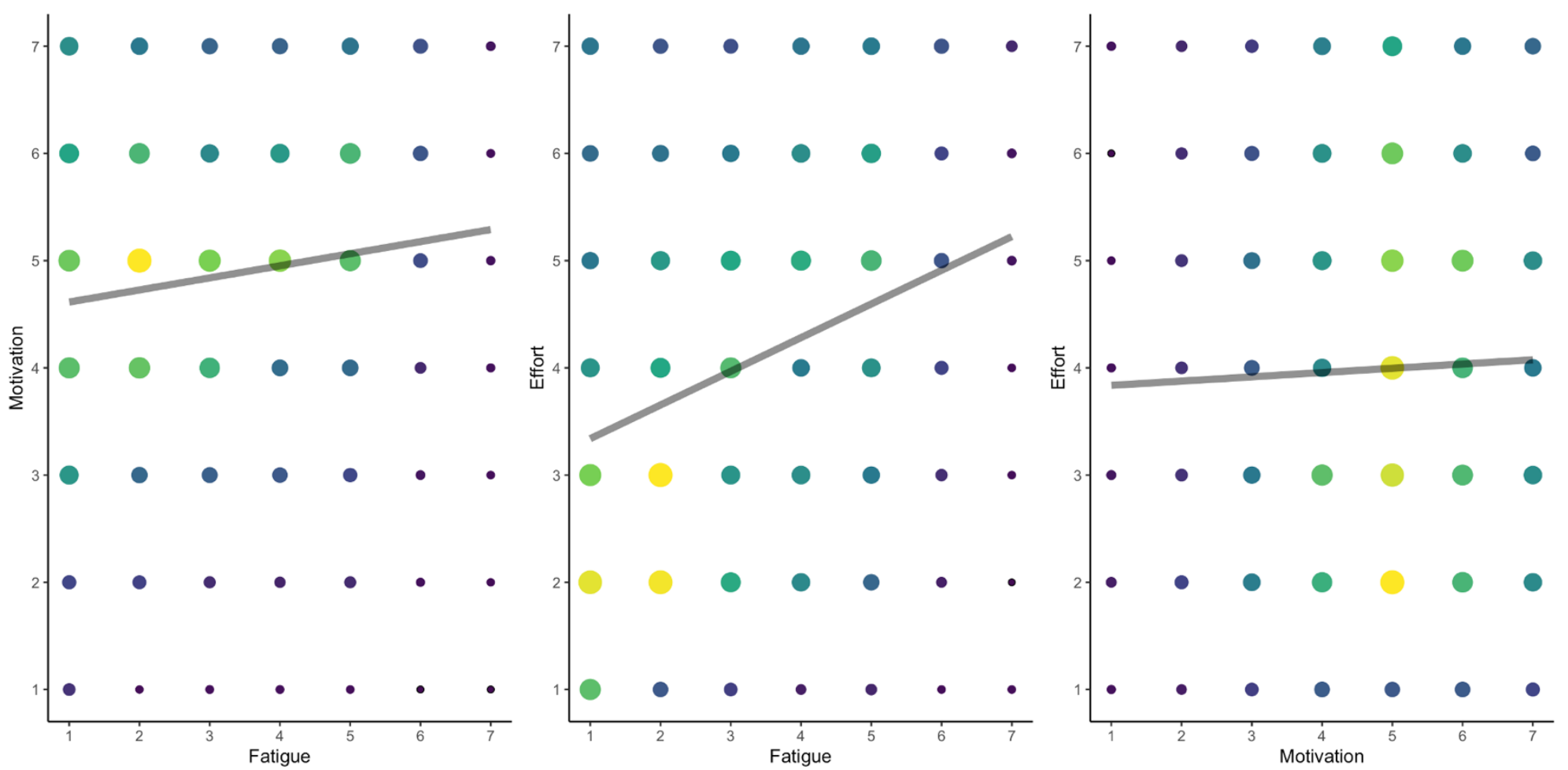

$n 50 \bigcirc 100 \bigcirc 150 \bigcirc 200$ 
Table 2. Correlations with confidence intervals between self-control resources (i.e., perceived fatigue), self-control capacity (i.e., inhibition), and self-control effort based on data from Lin et al. (2020)

\begin{tabular}{lcc}
\hline Variable & 1 & 2 \\
\hline 1. Perceived fatigue & & \\
2. Inhibition & $-.03 *$ & \\
& {$[-.05,-.00]$} & \\
3. Effort & $\mathbf{. 7 2 * *}$ & $\mathbf{. 0 2 *}$ \\
& {$[.71, .73]$} & {$[.00, .05]$} \\
\hline
\end{tabular}

Note. Values in square brackets indicate the $95 \%$ confidence interval for each correlation. The confidence interval is a plausible range of population correlations that could have caused the sample correlation (Cumming, 2014). * indicates $p<.05$. ** indicates $p<.01$. 
Figure 2. Correlations between self-control resources (i.e., perceived fatigue), self-control capacity (i.e., inhibitory control), and self-control effort based on data from Lin et al. (2020)
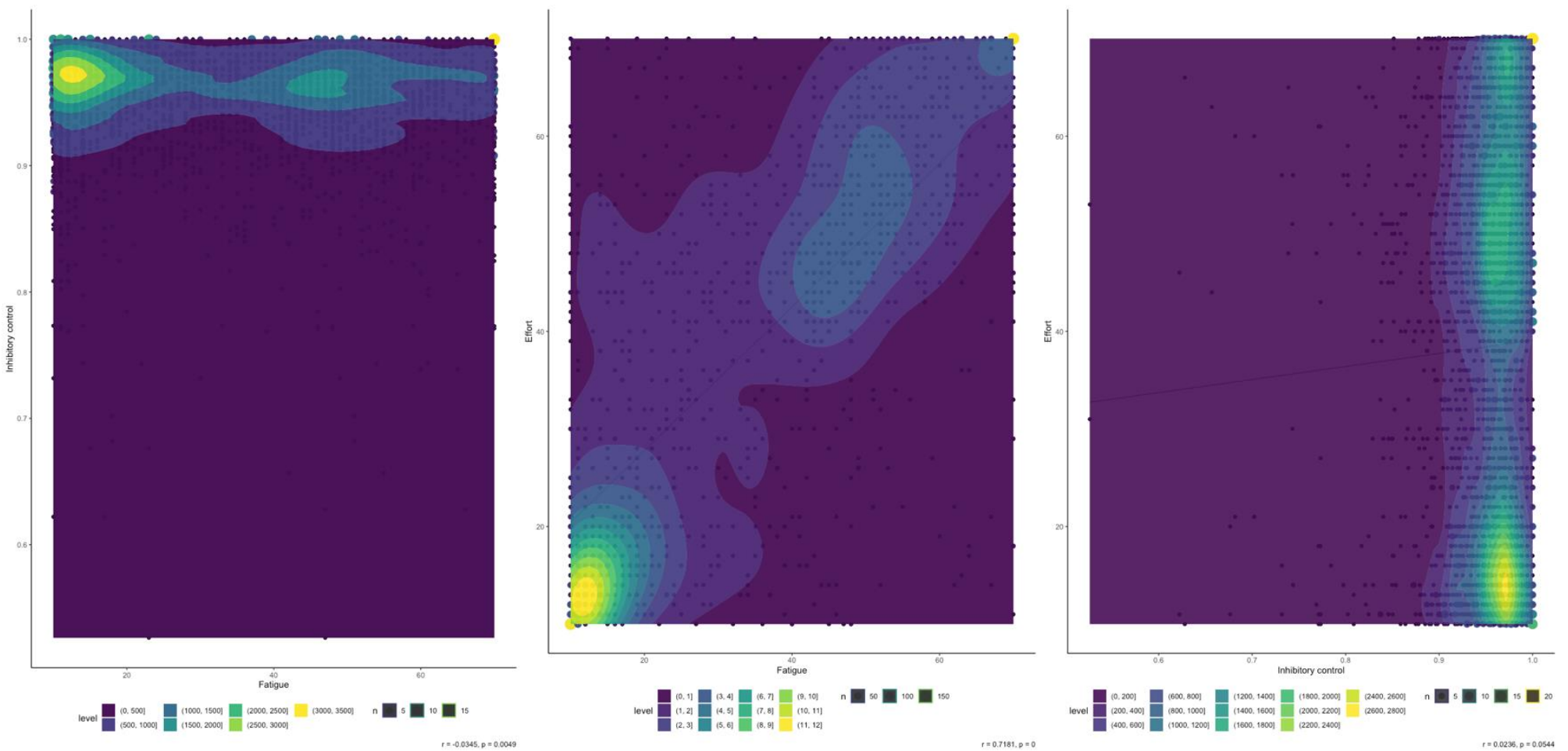
Figure 3. Shared variance between self-control capacity and self-control resources (right panel is based on data from Lin et al., 2020) as well as between self-control resources and self-control willingness (left panel is based on data from Vohs et al., 2021) suggesting small overlap
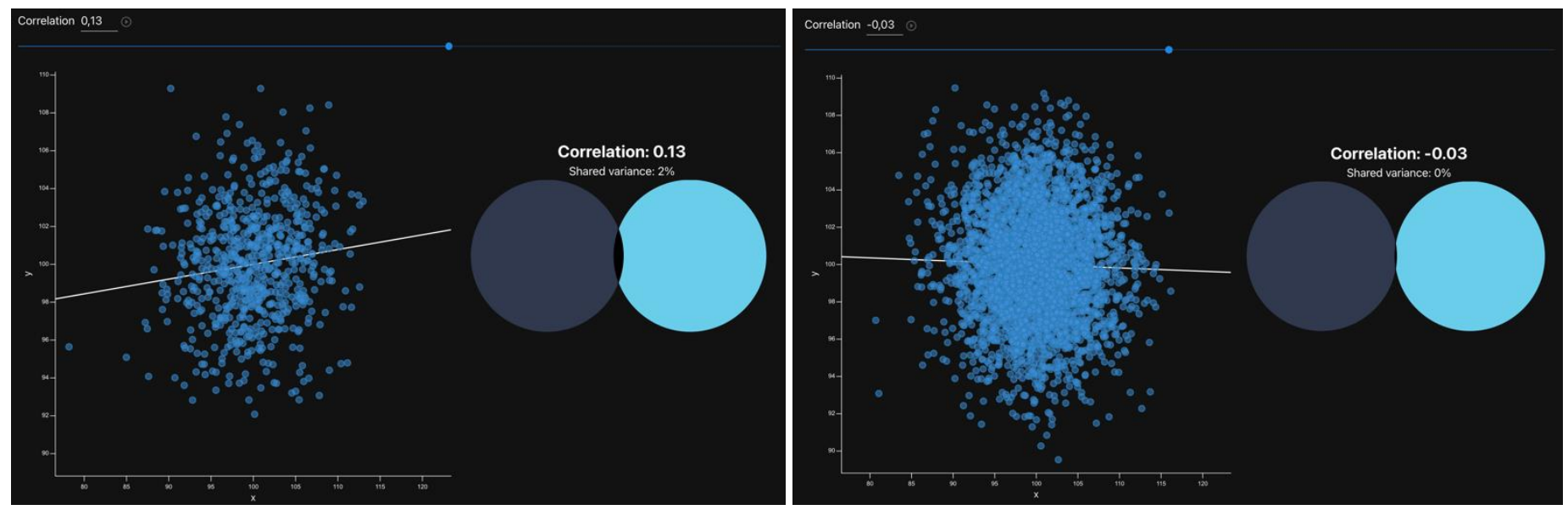